\title{
Cloud vertical distribution from combined surface and space radar-lidar observations at two Arctic atmospheric observatories
}

\author{
Yinghui Liu ${ }^{1}$, Matthew D. Shupe ${ }^{2}$, Zhien Wang ${ }^{3}$, and Gerald Mace ${ }^{4}$ \\ ${ }^{1}$ Cooperative Institute of Meteorological Satellite Studies, University of Wisconsin at Madison, Madison, WI, USA \\ ${ }^{2}$ Cooperative Institute for Research in Environmental Sciences, University of Colorado and NOAA Earth System \\ Research Laboratory, Boulder, CO, USA \\ ${ }^{3}$ Department of Atmospheric Science, University of Wyoming, Laramie, WY, USA \\ ${ }^{4}$ Atmospheric Sciences, University of Utah, Salt Lake City, UT, USA \\ Correspondence to: Yinghui Liu (yinghuil@ssec.wisc.edu)
}

Received: 22 December 2016 - Discussion started: 12 January 2017

Revised: 25 April 2017 - Accepted: 3 May 2017 - Published: 16 May 2017

\begin{abstract}
Detailed and accurate vertical distributions of cloud properties (such as cloud fraction, cloud phase, and cloud water content) and their changes are essential to accurately calculate the surface radiative flux and to depict the mean climate state. Surface and space-based active sensors including radar and lidar are ideal to provide this information because of their superior capability to detect clouds and retrieve cloud microphysical properties. In this study, we compare the annual cycles of cloud property vertical distributions from space-based active sensors and surface-based active sensors at two Arctic atmospheric observatories, Barrow and Eureka. Based on the comparisons, we identify the sensors' respective strengths and limitations, and develop a blended cloud property vertical distribution by combining both sets of observations. Results show that surface-based observations offer a more complete cloud property vertical distribution from the surface up to $11 \mathrm{~km}$ above mean sea level (a.m.s.l.) with limitations in the middle and high altitudes; the annual mean total cloud fraction from space-based observations shows $25-40 \%$ fewer clouds below $0.5 \mathrm{~km}$ than from surface-based observations, and space-based observations also show much fewer ice clouds and mixed-phase clouds, and slightly more liquid clouds, from the surface to $1 \mathrm{~km}$. In general, space-based observations show comparable cloud fractions between 1 and $2 \mathrm{~km}$ a.m.s.l., and larger cloud fractions above $2 \mathrm{~km}$ a.m.s.l. than from surface-based observations. A blended product combines the strengths of both products to provide a more reliable annual cycle of cloud property vertical distributions from the surface to
\end{abstract}

$11 \mathrm{~km}$ a.m.s.l. This information can be valuable for deriving an accurate surface radiative budget in the Arctic and for cloud parameterization evaluation in weather and climate models. Cloud annual cycles show similar evolutions in total cloud fraction and ice cloud fraction, and lower liquidcontaining cloud fraction at Eureka than at Barrow; the differences can be attributed to the generally colder and drier conditions at Eureka relative to Barrow.

\section{Introduction}

The Arctic has changed dramatically in recent decades, and causes of these changes and their feedbacks to the global climate system are under intense investigation. The Arctic is warming at a higher rate than that of the global average, a phenomenon known as Arctic amplification (Solomon et al., 2007; Serreze and Francis, 2006); Arctic sea ice extent has been decreasing dramatically (Serreze et al., 2015), and this trend is expected to continue (Holland and Bitz, 2003; Overland and Wang, 2013). Changes in the Arctic have likely led to changes in the weather and climate in the midlatitudes through teleconnections in the large-scale circulation (Francis and Vavrus, 2012). By studying the factors influencing the Arctic climate system and its changes, we will improve understanding of the Arctic climate and its relationship to the global climate system. The largest uncertainty in predicting the Arctic climate arises from our lack of understanding of the role clouds play in the Arctic climate system (Solomon 
et al., 2007; Boucher et al., 2013). A complete, accurate description of three-dimensional cloud properties is critical to determine the radiation flux both at the surface and at the top of atmosphere (TOA), as well as the radiative heating rate in the atmosphere. Examining and understanding changes in these vertical distributions are key to studying the recent Arctic changes.

Cloud products from space-based combined radar-lidar observations have the potential to provide comprehensive information on the vertical distribution of cloud properties. These observations have been used to describe global cloud spatial distributions and their temporal changes ( $\mathrm{Li}$ et al., 2015; Naud et al., 2015). However, space-based low-cloud observations are limited by radar ground clutter and strong attenuation of lidar signals, especially by liquid and mixedphase clouds (Marchand et al., 2008; Blanchard et al., 2014). Radar reflectivity from CloudSat has been used to generate high-vertical-resolution longwave and shortwave radiative flux profiles and corresponding heating rates (L'Ecuyer et al., 2008); assessing the product's accuracy shows that CloudSat's weakness in detecting low clouds introduces the largest uncertainty. This product has been improved by the inclusion of complementary cloud and aerosol information mainly from space-based lidar observations (Henderson et al., 2013). Complementing the space-based observations, surface observations have superior performance near the surface (Shupe et al., 2011; Shupe, 2011; Zhao and Wang, 2010) and in resolving the diurnal cycle at a specific location, with a relatively weaker performance in the middle and upper levels.

Efforts have been made to investigate the differences in cloud fraction/frequency from surface-based and spacebased radar-lidar combined observations and their impact on the radiative fluxes at multiple surface stations. Using such observations, Protat et al. (2014) studied the cloud occurrence frequency around Darwin, Australia, and found that space-based observations underestimated the cloud occurrence frequency below $2 \mathrm{~km}$ above mean sea level (a.m.s.l.; hereafter, all heights are in kma.m.s.l.), while surface observations do not detect most of the cirrus clouds above $10 \mathrm{~km}$. Blanchard et al. (2014) investigated the difference in cloud fraction and vertical distribution at Eureka, Canada, in the Arctic from surface and space-based combined radarlidar observations from 2006 to 2010. Among many valuable findings, they found that space-based radar-lidar measurements can depict a complete picture of the cloud vertical profile down to $2 \mathrm{~km}$. Mioche et al. (2015) compared vertical profiles of cloud occurrences from surface lidar and spacebased lidar, radar, and combined lidar and radar over the $\mathrm{Ny}$ Ålesund station during March and April 2007, and showed similar results above $2 \mathrm{~km}$ as those in Blanchard et al. (2014). The strengths and limitations of these observations are also discussed in other papers, e.g., Kay et al. (2008), Kay and Gettleman (2009), and Huang et al. (2012).

This study focuses on further examining and comparing the performance of space-based and surface-based radar- lidar observations and retrievals to capture the vertical distribution of cloud properties, including cloud fraction, cloud phase, and cloud water content, at two Arctic atmospheric observatories, Barrow, Alaska (USA), and Eureka, Canada. Since cloud phase has been shown to have a particularly strong impact on Arctic cloud radiative effects on the surface (Shupe and Intrieri, 2004), it is particularly important to understand how differences in viewing geometry impact observations of different cloud phases. Differences between spacebased and surface-based clouds (ice clouds, liquid clouds, and mixed-phase clouds) amounts, and cloud ice and liquid water contents are shown in terms of monthly means. Based on the comparison performed here, this study also proposes blended products of cloud property vertical distributions from surface and space-based cloud observations at those two Arctic sites to serve as a best estimate cloud product for model and reanalysis evaluation.

Space-based radar and lidar in this paper refer to existing instruments, i.e., the Cloud Profiling Radar (CPR) onboard the CloudSat and the Cloud-Aerosol LIdar with Orthogonal Polarization (CALIOP) onboard the Cloud-Aerosol lidar and Infrared Pathfinder Satellite Observation (CALIPSO). However, the conclusions will likely be valid for other spacebased radar and lidar instruments, e.g., the ATmospheric backscatter LIDar (ATLID) and the CPR onboard the EarthCARE mission (Hélière et al., 2007).

\section{Data and method}

From the possible Arctic atmospheric observation sites, we have selected Barrow $\left(71^{\circ} 19^{\prime} \mathrm{N}, 156^{\circ} 37^{\prime} \mathrm{W}\right)$ and Eureka $\left(80^{\circ} 80^{\prime} \mathrm{N}, 85^{\circ} 57^{\prime} \mathrm{W}\right)$ because of the availability of daily cloud vertical profiles from surface observations from 2006 to 2010 when space-based observations are available. The combined radar-lidar cloud fraction best estimation, cloud fraction vertical profiles, cloud phase vertical profiles, and cloud water content vertical profiles, from surface observations at these two sites, are described in detail in Shupe et al. $(2011,2015)$ and Shupe $(2011)$. These products are based on coincident measurements from the Ka-band cloud radar, depolarization lidars including the micropulse lidar (MPL) at Barrow, and the high-spectral-resolution lidar (HSRL) at Eureka, microwave radiometer, and radiosondes, which are combined to determine cloud phase (Shupe, 2007) and microphysical properties at $1 \mathrm{~min}$ temporal and $100 \mathrm{~m}$ vertical resolutions.

Observations from CloudSat and CALIPSO provide an unprecedented opportunity for a spatially extensive picture of cloud cover in the Arctic (Stephens et al., 2002; Winker et al., 2003). The Vertical Feature Mask (VFM) version 3.01 from CALIPSO's CALIOP provides cloud vertical distribution in up to 10 vertical layers at 5 and $1 \mathrm{~km}$ horizontal resolutions, and up to 5 vertical layers at $1 / 3 \mathrm{~km}$ horizontal resolution (Vaughan et al., 2009). The vertical resolution is $30 \mathrm{~m}$ 
(a) Barrow surface (\%)

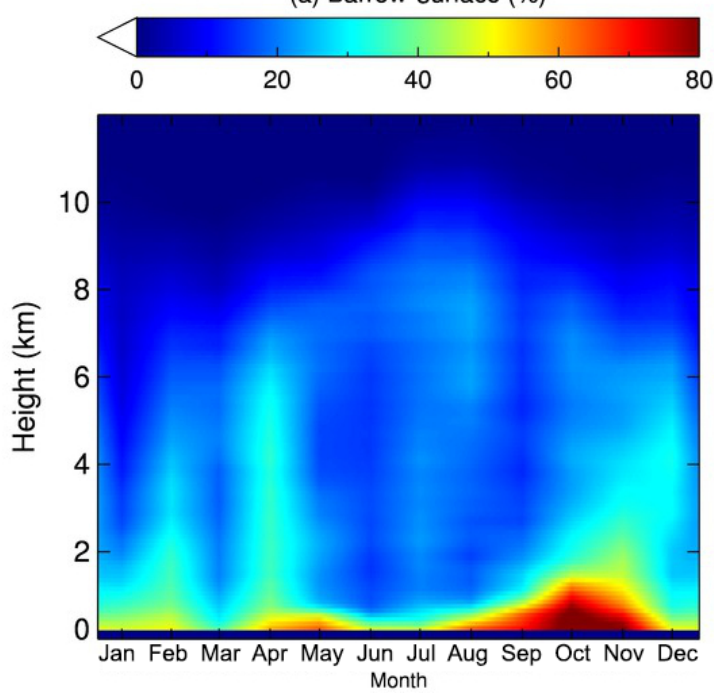

(b) Eureka surface (\%)

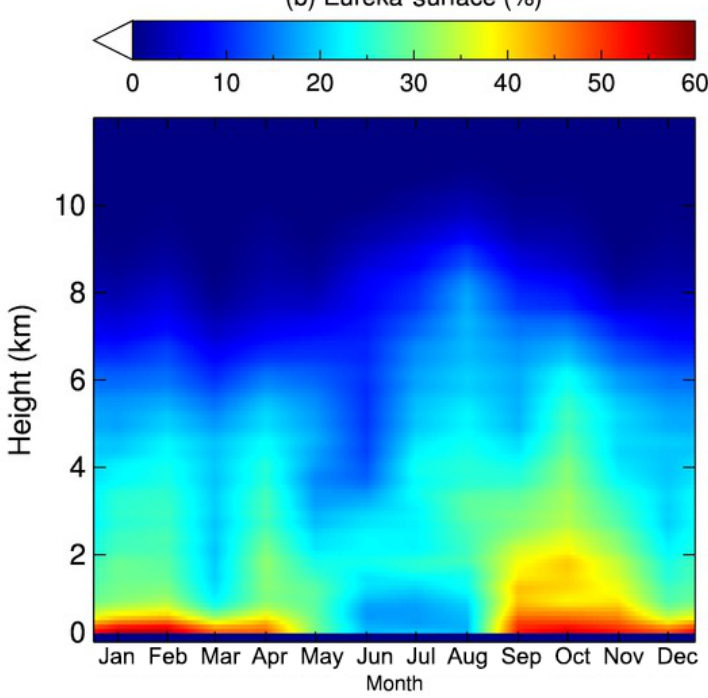

Figure 1. Cloud fraction vertical distribution from surface observations at (a) Barrow and (b) Eureka for 2006-2010 (after Shupe et al., 2011).

below $8.2 \mathrm{~km}$, and $60 \mathrm{~m}$ between 8.2 and $20.2 \mathrm{~km}$. A Selective Iterated BoundarY Location (SIBYL) scheme is applied to detect all features within a given scene. Strongly scattering features, e.g., stratus clouds, can be identified in a single laser pulse, with the $1 / 3 \mathrm{~km}$ horizontal resolution, and these features are then removed in order to detect any surrounding aerosol layers. Weakly scattering features, e.g., thin cirrus clouds, are detected with the average of several laser pulses, e.g., $5 \mathrm{~km}$ horizontal resolution, for higher signal-tonoise ratio (Vaughan et al., 2005). Compared to the $1 \mathrm{~km}$ resolution data, the $5 \mathrm{~km}$ resolution product can identify weaker cloud features (Vaughan et al., 2009). Combining the cloud layer products at 5 and $1 / 3 \mathrm{~km}$ provides a complete vertical distribution of clouds from CALIPSO (Vaughan et al., 2005, 2009). The newly available VFM version 4.10 reports the spatial and optical properties all cloud layers detected at $5 \mathrm{~km}$ averaging resolution, and combination of VFM at 5 and $1 / 3 \mathrm{~km}$ is no longer needed for a complete cloud vertical distribution. In this study, the CALIPSO products (version 3.01) from June 2006 to December 2010 were obtained from the Atmospheric Science Data Center at NASA Langley Research Center.

The CPR onboard CloudSat also provides an echo mask, in the variable "CPR_Cloud_mask" at 125 vertical range bins, with a bin size of $240 \mathrm{~m}$, in a product known as the Level 2 geometrical profiling product (2B-GEOPROF; Marchand et al., 2008). The latest CloudSat cloud mask (R04) has negligible surface contamination from about $0.96 \mathrm{~km}$ above the surface. Due to the surface clutter, only strong cloud or precipitation signals can be detected in the lowest approximately $0.7 \mathrm{~km}$, while weaker cloud signals are missed. In this study, a range bin is defined as clouds when the CPR_Cloud_mask is equal to or larger than 20 , which includes weak echo, good echo, and strong echo. Very weak echo and echo with likely surface clutter are not included. This threshold is the same as that used in the Radar-Lidar Geometrical Profile Product 2B-GEOPROF-lidar (Mace et al., 2009; Mace and Zhang, 2014), and a false positive detection of $5 \%$ is estimated with this threshold in the 2B-GEOPROF-lidar (Mace et al., 2009). The 2B-GEOPROF-lidar merges the CloudSat GEOPROF (Marchand et al., 2008) and the CALIPSO VFM (Vaughan et al., 2009). The 2B-GEOPROF-lidar contains parameters for up to five hydrometeor layers, including the cloud base and cloud top heights above mean sea level for each hydrometeor layer in one radar footprint along with the longitude and latitude.

A Level 2 combined product, 2B-CLDCLASS-lidar, combines CPR and CALIOP measurements for cloud phase determination into eight basic cloud types (Sassen and Wang, 2012). Ice, water/liquid, and mixed-phase clouds are identified for up to 10 layers. The 2B-CLDCLASS-lidar collocates CALIOP L1 measurements to CPR footprints, then determines cloud vertical structures (Wang et al., 2008) and cloud phase. The microphysical property differences between water and ice particles, including size, location, falling speed, and number concentrations, result in large differences in their radiative properties, and in turn large differences in the CALIPSO lidar and CloudSat CPR signals. Cloud phase is effectively determined using the different sensitivities of CloudSat radar and CALIPSO lidar to ice crystals and water droplets, together with the cloud top and cloud base temperatures.

Based on the measured CPR radar reflectivity factor, another Level 2 product, the CloudSat Radar-Only Cloud Water Content product (2B-CWC-RO), estimates cloud liquid and ice water content, as well as effective radius. Effective radius 

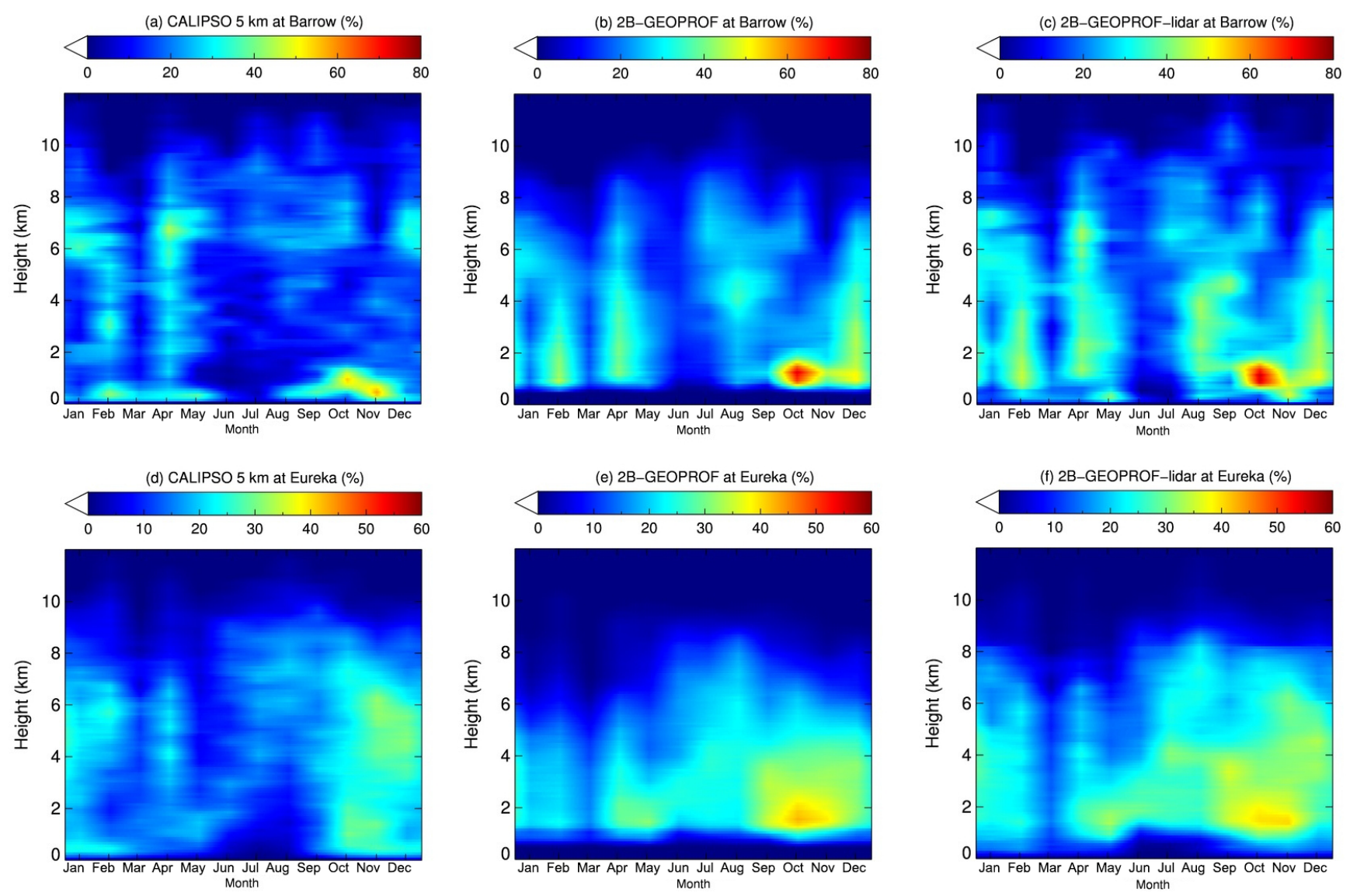

Figure 2. Cloud fraction vertical distribution 2006-2010 from (a) CALIPSO $5 \mathrm{~km}$, (b) 2B-GEOPROF, and (c) 2B-GEOPROF-lidar at Barrow; (d) CALIPSO $5 \mathrm{~km}$, (e) 2B-GEOPROF, and (f) 2B-GEOPROF-lidar at Eureka.

and water content are retrieved based on the assumption that the radar profile is due to a single phase of water, either liquid or ice. Using a simple scheme based on a model temperature profile, this product combines separate liquid and ice profiles into a mixture of ice and liquid phases over a portion of the vertical profile within the proper temperature range. The temperature profile is obtained from European Centre for Medium-Range Weather Forecasts (ECMWF) reanalysis data that have been collocated in space and time to the CloudSat radar profile and interpolated to the CloudSat vertical resolution. It should be noted that the retrieval is not designed to determine mixed-phase cloud properties directly.

In this study, vertical profiles of cloud fraction from CALIPSO at $1 / 3,1$, and $5 \mathrm{~km}$ horizontal resolution, $2 \mathrm{~B}$ GEOPROF and 2B-GEOPROF-lidar, vertical profiles of cloud phase (ice, liquid, and mixed phase) from 2BCLDCLASS-lidar, and vertical profiles of cloud effective radius and water content from 2B-CWC-RO are calculated and examined. Vertical profiles of all these products within $50 \mathrm{~km}$ of the two Arctic atmospheric observation sites, Barrow and Eureka, are extracted and archived. The cloud fraction vertical distribution at a resolution of $30 \mathrm{~m}$ is calculated as follows. The mean cloud fraction at each vertical level is cal- culated as the ratio of the number of profiles with clouds detected at a particular vertical level to the total number of profiles. The cloud vertical distributions from CALIPSO at $1 / 3$ and $5 \mathrm{~km}$ are calculated first, then combined as the mean of the cloud fractions at each vertical level. This combined product, referred as CALIPSO $5 \mathrm{~km}$, provides a complete vertical distribution of clouds from CALIPSO and is shown in Sect. 3. For comparison, the vertical profiles of cloud fractions from CALIPSO at $1 / 3$ and $1 \mathrm{~km}$ are also combined (referred to as CALIPSO $1 \mathrm{~km}$ ) and shown in Sect. 3. For cloud microphysical property vertical distribution, the mean cloud phase frequency at each vertical level is calculated as the ratio of the number of profiles with each phase to the total number of profiles. Mean cloud water content for the ice (liquid) phase at each vertical level is calculated as the mean value of water content from all available ice (liquid) cloud retrievals at that level. To derive these statistics, ice in any type of clouds (ice and mixed phase) is included, while liquid in any type of clouds (liquid and mixed phase) is included, respectively. After this step, the vertical resolution of all products is $30 \mathrm{~m}$. Total cloud (ice clouds, liquid clouds, mixed-phase clouds) amounts are also calculated as the ratio of the number of profiles with clouds (ice clouds, liquid 

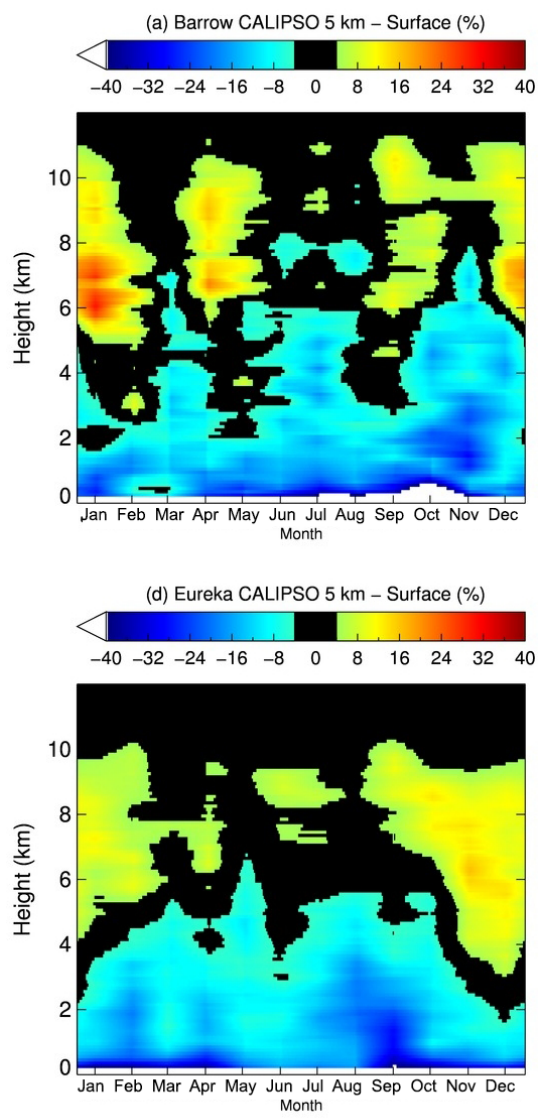
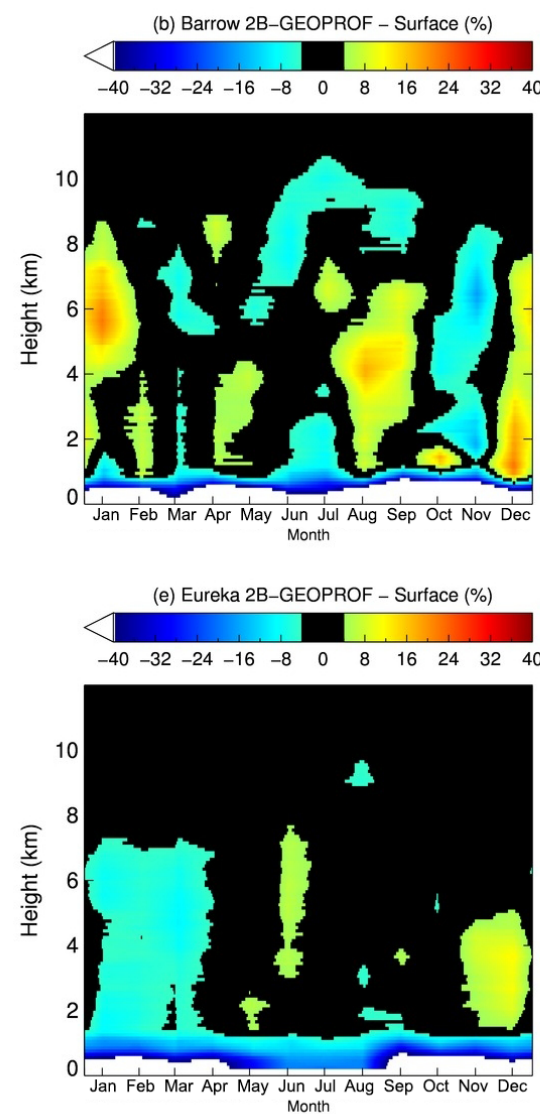
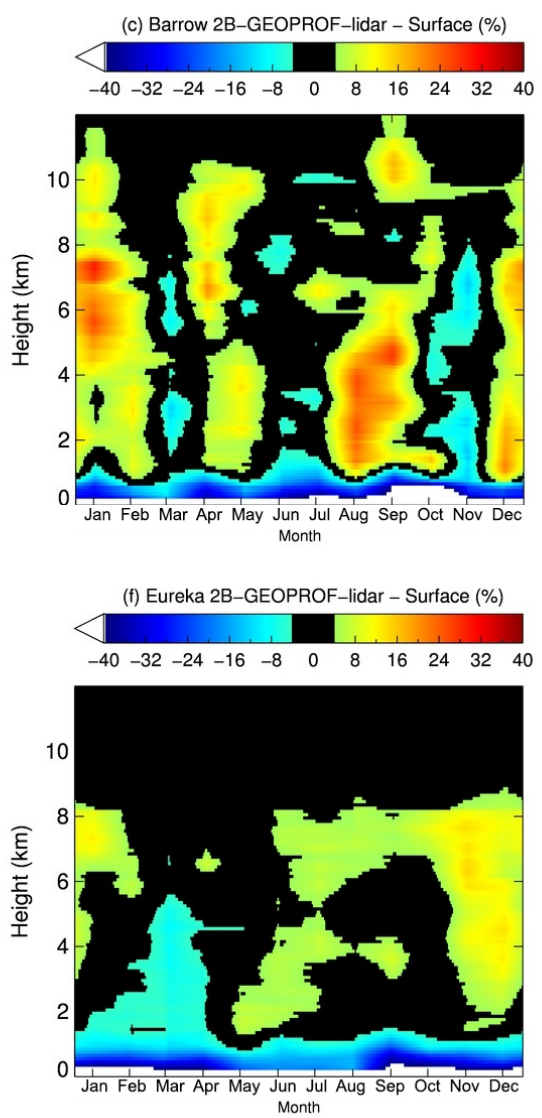

Figure 3. Cloud fraction vertical distribution difference for 2006-2010 from (a) CALIPSO $5 \mathrm{~km}$, (b) 2B-GEOPROF, and (c) 2B-GEOPROFlidar and surface observations at Barrow; from (d) CALIPSO $5 \mathrm{~km}$, (e) 2B-GEOPROF, and (f) 2B-GEOPROF-lidar and surface observations at Eureka.

clouds, mixed-phase clouds) detected in any layer to the total number of profiles.

Surface-based radar, lidar, and radar-lidar combined products are available from June 2006 to December 2010. Details of the collection and processing of the data can be found in Shupe (2011) and Shupe et al. (2011, 2015). Surface observations of good quality are available at Eureka for most of this time period and at Barrow from mid-February 2008 to December 2010. Hereafter, "observations at Barrow and Eureka from 2006 to 2010" refers to observations at Barrow from June 2006 to December 2010 and observations at Eureka from mid-February 2008 to December 2010. For consistency, the space-based results are considered over the same time periods as the available surface observations at each site. Monthly means are calculated for both surface observations and for the space-based sensors. All heights are above the mean sea level. All surface profiles in a month are accumulated to calculate monthly means. The monthly mean sample number of the satellite sensors is a function of latitude in the Arctic, with the fewest at $60^{\circ} \mathrm{N}$, gradually increasing to a maximum around $80^{\circ} \mathrm{N}$ (Liu, 2015). Both factors are re- flected in the large number of samples at Eureka, with over 6000 total samples per month from June 2006 to December 2010 in contrast to around 1500 total samples at Barrow per month from mid-February 2008 to December 2010. The vertical resolution of the calculated space-based monthly means is interpolated to $100 \mathrm{~m}$ to be consistent with and compared to those from surface observations.

\section{Results}

\subsection{Cloud fraction vertical distribution}

\subsubsection{Barrow}

Cloud fraction vertical distributions from surface observations at Barrow (Fig. 1a) reveal that cloud fractions are greater than $30 \%$ at each layer below $0.5 \mathrm{~km}$ throughout the year, except in March and June. In the lower levels (surface to $2 \mathrm{~km}$ ), the cloud fraction vertical distributions show maximum values between 55 and $85 \%$ in October and November. In the middle level ( 2 to $6 \mathrm{~km}$ ), most of the cloud fractions are 
less than $30 \%$, except the local maxima is greater than $30 \%$ in April and November. Minimal cloud fractions of less than $15 \%$ occur above $4 \mathrm{~km}$ in January, June, and September. In the higher levels ( 6 to $12 \mathrm{~km}$ ), most cloud fractions are less than $20 \%$, except those between 6 and $8 \mathrm{~km}$ in April, August, and October.

The space-based observations show similar patterns but different values as compared to surface observations at Barrow (Fig. 2a, b, c). CloudSat 2B-GEOPROF (Fig. 2b) shows few clouds below $0.5 \mathrm{~km}$ because of the surface clutter issue, limited cloud distribution between 0.5 and $1 \mathrm{~km}$, and patterns similar to the surface observations above $1 \mathrm{~km}$. CALIPSO $5 \mathrm{~km}$ (Fig. 2a) shows considerably higher cloud fractions than CALIPSO $1 \mathrm{~km}$ (figure not shown) throughout, and both products show some cloud fraction distribution below $0.5 \mathrm{~km}$. The 2B-GEOPROF-lidar (Fig. 2c) cloud vertical distribution merges information from both CloudSat and CALIPSO, thus providing a more complete vertical distribution than either of those two alone. It is worth pointing out that the 2B-GEOPROF-lidar shows higher cloud amount values from 1 to $5 \mathrm{~km}$ in the troposphere than the sum of cloud amounts from 2B-GEOPROF and CALIPSO $5 \mathrm{~km}$. The differences can be partially attributed to the attenuation of the CALIOP signal and a large number of thin clouds in the middle and lower troposphere (Devasthale et al., 2011). Though investigating attribution is beyond the scope of this study, it is worth further investigation in future studies. Based on the 2B-GEOPROF-lidar cloud vertical distribution, the cloud fraction below $0.5 \mathrm{~km}$ is less than $30 \%$ most of the year, except in May and November when the local maximum is greater than $30 \%$. In the lower levels, cloud fraction increases with height, reaching a maximum between 1 and $1.5 \mathrm{~km}$, and then decreasing in general. At this level, the annual minimum cloud fraction (less than $20 \%$ ) appears in June and July. In the middle levels, cloud fractions are mostly between 20 and $40 \%$. The maximum cloud fraction appears in April, August, and December with values greater than $35 \%$. The minimum appears in March and June with values less than $16 \%$. In the higher levels, cloud fractions are often $20 \%$ or more, except for November, March, and June.

Comparing cloud vertical distributions from space-based observations and surface observations at Barrow shows the overall least cloud fraction from CALIPSO $1 \mathrm{~km}$, then CALIPSO $5 \mathrm{~km}$, and 2B-GEOPROF, with the overall greatest cloud fraction from 2B-GEOPROF-lidar above $1 \mathrm{~km}$, while all space-based cloud fractions are less than those from surface observations in the lowest $1 \mathrm{~km}$ (Figs. 2 and 3). Compared to the cloud fraction vertical distribution from surface observations, CALIPSO $1 \mathrm{~km}$ shows less cloud fraction in every month from the surface to $6-11 \mathrm{~km}$ depending on the month (figure not shown); CALIPSO $5 \mathrm{~km}$ shows less cloud fraction from the surface to $5 \mathrm{~km}$ in every month, and larger cloud fraction above $6 \mathrm{~km}$ in most months. Above $1 \mathrm{~km}, 2 \mathrm{~B}-$ GEOPROF differs from the surface observations by +20 to
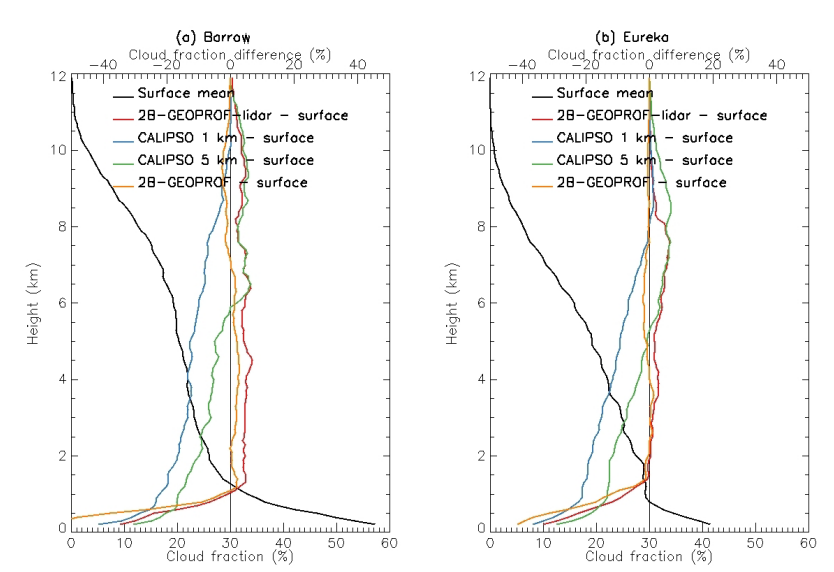

Figure 4. Mean vertical distributions of cloud fraction from surface observations and the difference of 2B-GEOPROF-lidar, CALIPSO $1 \mathrm{~km}$, and CALIPSO $5 \mathrm{~km}$, and 2B-GEOPROF minus surface observations at (a) Barrow and (b) Eureka for 2006-2010.

$-10 \%$. In most months, 2B-GEOPROF-lidar tends to have larger cloud fractions above $1 \mathrm{~km}$; all space-based cloud fractions show lower cloud fractions below $1 \mathrm{~km}$, with the lowest from 2B-GEOPROF, then CALIPSO $1 \mathrm{~km}$, CALIPSO $5 \mathrm{~km}$, and 2B-GEOPROF-lidar. The near-surface cloud distributions from 2B-GEOPROF-lidar originate from CALIPSO observations and also show much lower cloud fraction distributions below $0.5 \mathrm{~km}$, with differences as high as $-67 \%$ in October. The difference becomes smaller between 0.6 and $1.2 \mathrm{~km}$. Above $1.2 \mathrm{~km}, 2 \mathrm{~B}$-GEOPROF-lidar shows generally higher cloud fractions (up to $27 \%$ in September at $5 \mathrm{~km}$ ) than those from surface observations.

Comparing the annual mean cloud vertical distributions from space-based observations and surface observations shows that all space-based observations have lower cloud fractions in the lowest $1 \mathrm{~km}$, while 2B-GEOPROF-lidar and CALIPSO $5 \mathrm{~km}$ have higher cloud fractions at some heights above $1 \mathrm{~km}$ (Fig. 4a). More specifically, below $0.5 \mathrm{~km}$, the space-based observations see $25-40 \%$ fewer clouds than are observed from the surface; between 1 and $6 \mathrm{~km}, 2 \mathrm{~B}-\mathrm{GEOPROF}$ and 2B-GEOPROF-lidar show slightly greater cloud fractions, while CALIPSO 1 and $5 \mathrm{~km}$ show lower cloud fractions; above $6 \mathrm{~km}$, CALIPSO $5 \mathrm{~km}$ and 2BGEOPROF-lidar show slightly greater cloud fractions, while CALIPSO $1 \mathrm{~km}$ and 2B-GEOPROF show lower cloud fractions. For 2B-GEOPROF-lidar, the greater cloud fractions above $1 \mathrm{~km}$ are due to the combined detection capabilities of CALIPSO $5 \mathrm{~km}$ and 2B-GEOPROF. The low cloud fractions from space observations below $1 \mathrm{~km}$ can be attributed to the surface clutter issue from 2B-GEOPROF and the inability of CALIPSO to penetrate optically thick clouds. Surface observations reporting lower cloud fractions above $1 \mathrm{~km}$ might be due to the inability of surface lidar to penetrate lower-level optically thick liquid and mixed-phase clouds, along with the 

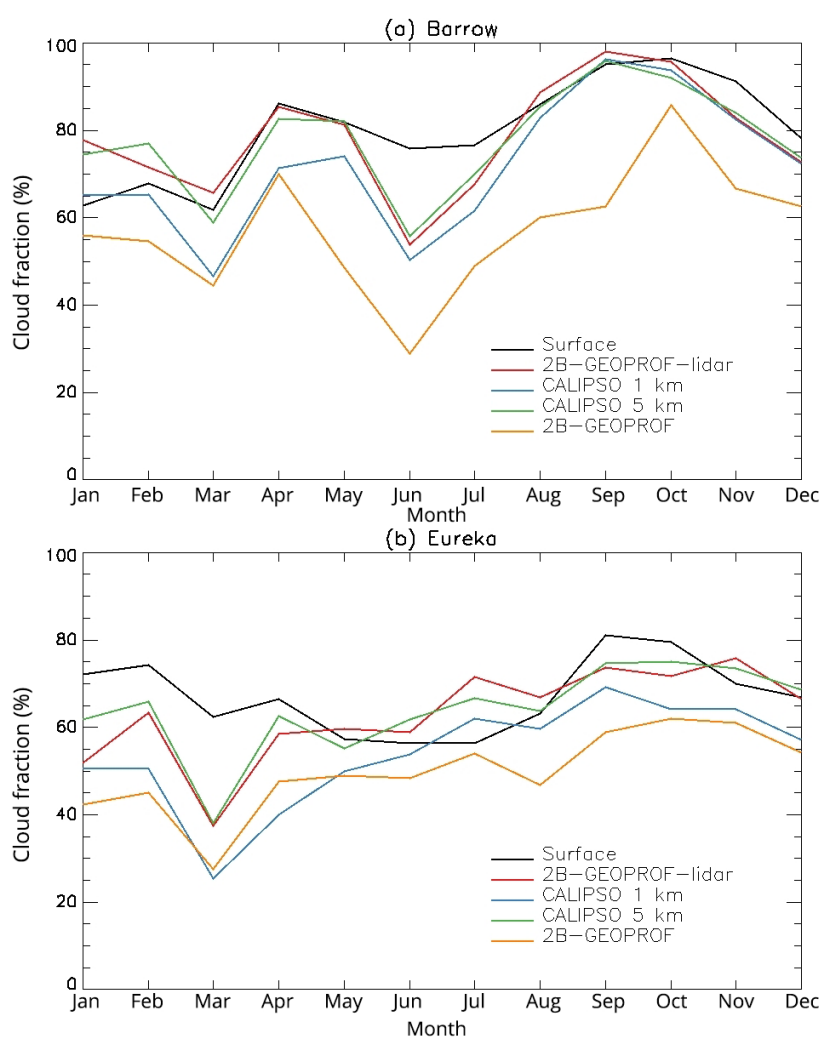

Figure 5. Monthly mean cloud fraction from surface observations, 2B-GEOPROF-lidar, CALIPSO $1 \mathrm{~km}$, CALIPSO $5 \mathrm{~km}$, and 2BGEOPROF at (a) Barrow (top) and (b) Eureka (bottom) for 20062010.

difficulty to detect optically thin clouds composed of small ice particles in the middle and upper levels by surface radar.

The annual cycle of monthly mean total cloud amount at Barrow shows relatively low values from January to March and relatively high values (75\% and higher) from April to December (Fig. 5a). Monthly means from space observations and surface observations share similarities, except 2B-GEOPROF shows much lower fractions in all months, e.g., around $30 \%$ in June compared to above $75 \%$ from surface observations. The annual cycle of $2 \mathrm{~B}-\mathrm{GEOPROF}-$ lidar is the most similar to that of surface observations, with lower monthly means from CALIPSO $5 \mathrm{~km}$, followed by CALIPSO $1 \mathrm{~km}$, and with 2B-GEOPROF showing the lowest values and the largest negative differences from May to September. This is in agreement with results presented in Zygmuntowska et al. (2012), considering that CloudSat does not detect clouds below approximately $0.5 \mathrm{~km}$. The larger differences from May to September might be attributed to the relatively higher frequency of clouds below $960 \mathrm{~m}$ in that time period (Fig. 6), which CloudSat does not detect well.

Vertical distributions of ice clouds, liquid clouds, and mixed-phase clouds at Barrow from 2006 to 2010 from surface observations are shown in Fig. 7 (Shupe, 2007; 2011). The main features include the following: ice clouds are

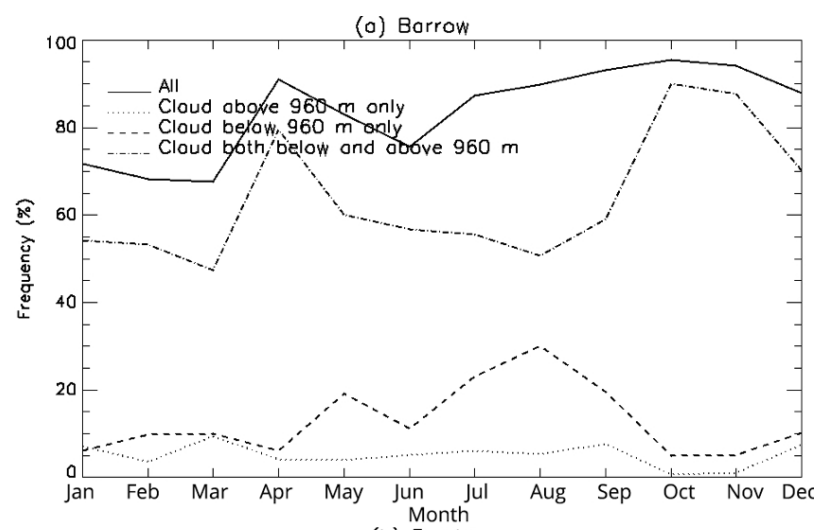

(b) Eurek

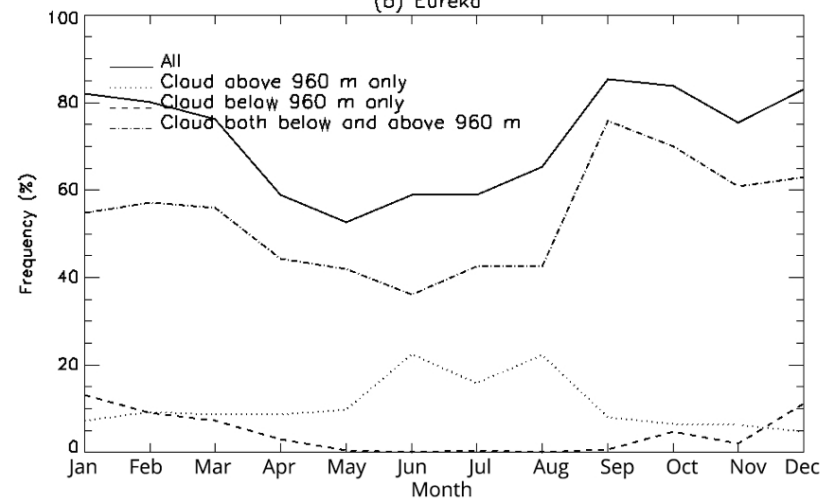

Figure 6. Mean cloud fraction above $960 \mathrm{~m}$ only, clouds below $960 \mathrm{~m}$ only, and clouds below and above $960 \mathrm{~m}$ from surface observations at Barrow (top) and Eureka (bottom) for 2006-2010.

prevalent from the surface up to $9-11 \mathrm{~km}$ throughout the year, except in June, July, and August, from the surface to $4.5 \mathrm{~km}$. The maximum ice cloud fractions occur in the lower levels from October to April and in the middle levels in April, November, and December with a range between 10 and $30 \%$. In the higher levels, ice cloud fractions between 10 and $20 \%$ appear from June to August. Mixed-phase clouds generally average $8-20 \%$ in the lower levels and for middle levels average $2-8 \%$. The maximum mixed-phase cloud fractions, up to $57 \%$, appear between the surface and $1 \mathrm{~km}$ from September to November. Liquid clouds appear between the surface and $0.8 \mathrm{~km}$ in the warm season mainly from May to September, with a maximum liquid cloud fraction (greater than $40 \%$ ) in the lowest $0.4 \mathrm{~km}$ in August.

Cloud phase vertical distributions at Barrow derived with 2B-CLDCLASS-lidar agree in general with the patterns observed above $1 \mathrm{~km}$ from surface observations (Fig. 7). At Barrow, ice clouds are common throughout the year from 1 up to $11 \mathrm{~km}$, except from June to August from the surface to $4.5 \mathrm{~km}$, when the ice cloud fractions are mostly less than $7 \%$. Liquid cloud fractions greater than $10 \%$ appear mainly from the surface to $0.8 \mathrm{~km}$ in May, August, September, and November. Mixed-phase clouds appear between 1 and $3.5 \mathrm{~km}$ throughout the year with a maximum (up to $55 \%$ ) appearing 

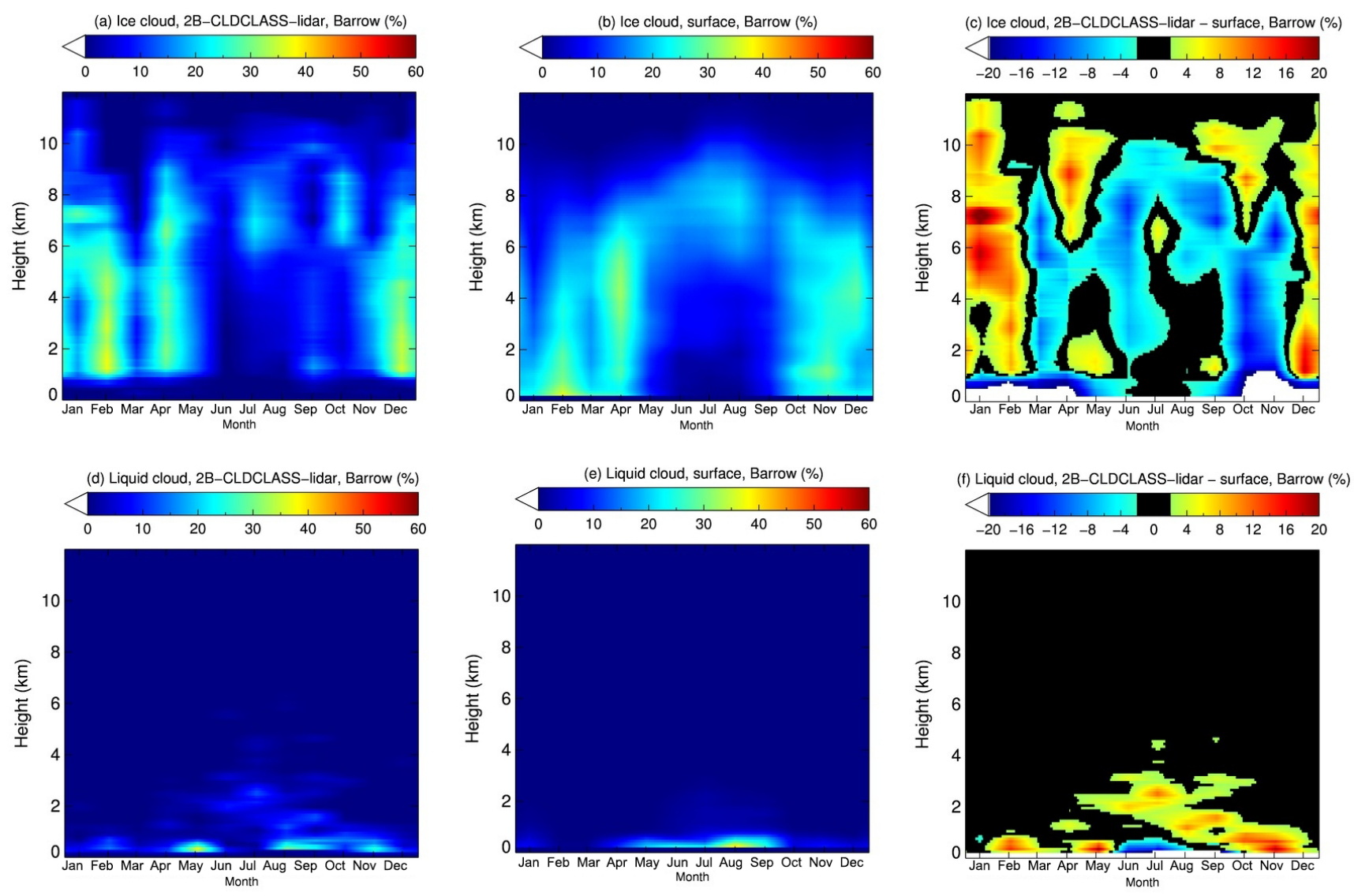

(g) Mixed phase cloud, 2B-CLDCLASS-lidar, Barrow (\%)
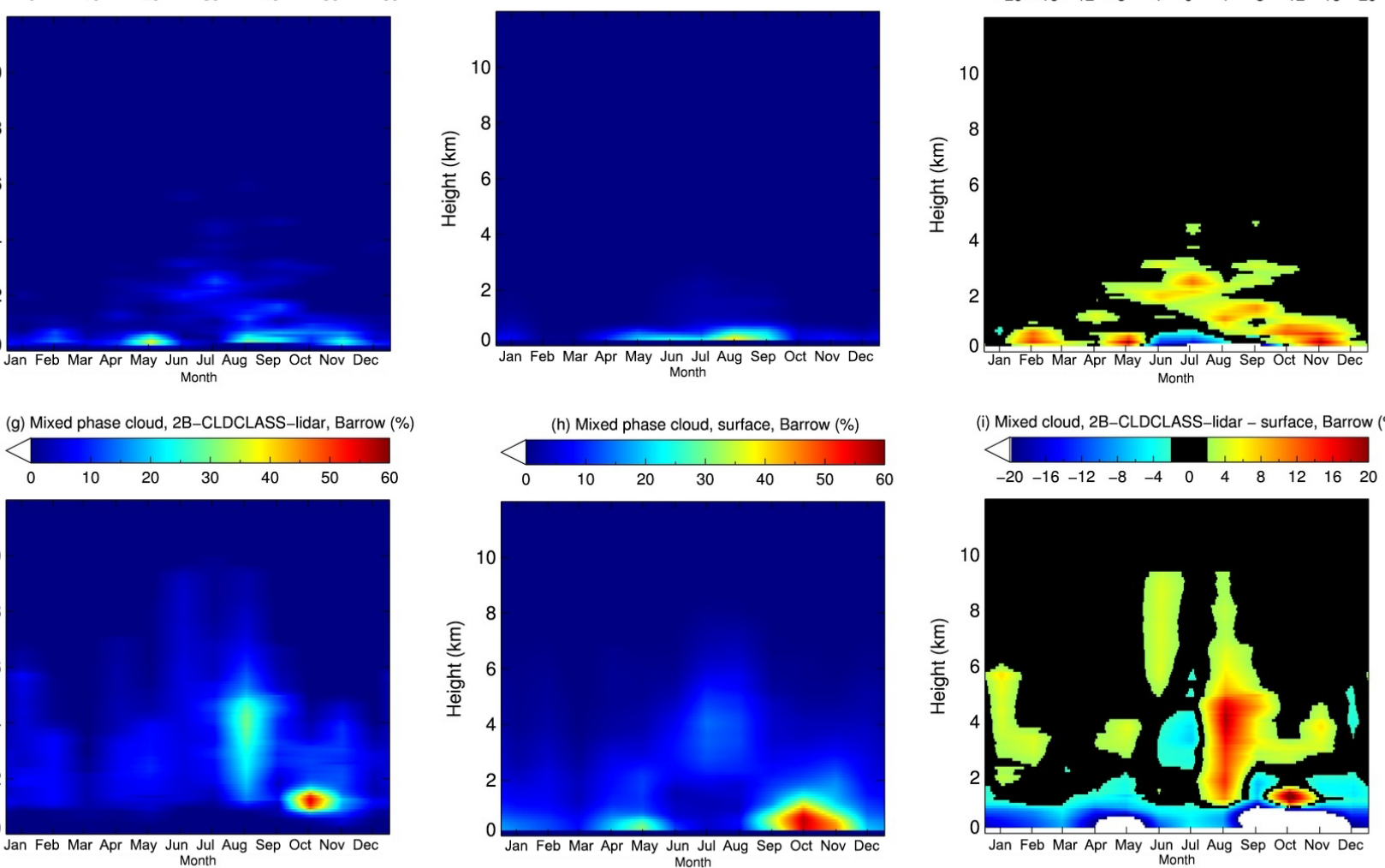

(i) Mixed cloud, 2B-CLDCLASS-lidar - surface, Barrow (\%)
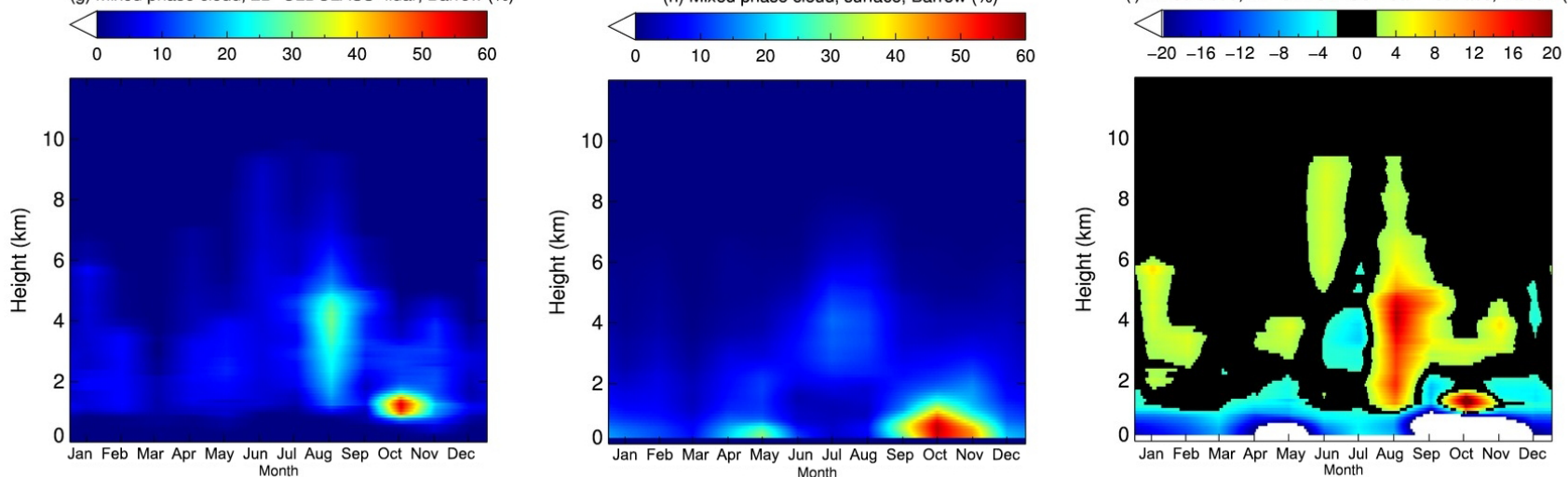

Figure 7. Vertical distributions of ice phase clouds (a-c), liquid phase clouds (d-f), and mixed-phase clouds (g-i) from 2B-CLDCLASSlidar (a, d, g), from surface observations $(\mathbf{b}, \mathbf{e}, \mathbf{h})$, and the difference of 2B-CLDCLASS-lidar and surface observations at Barrow for 2006-2010.

at $1 \mathrm{~km}$ in October. Another local maximum between 15 and $30 \%$ extends from 1 to $6 \mathrm{~km}$ in August, which is not shown in the surface observations. There is little mixed-phase cloud distribution below $1 \mathrm{~km}$.

One major difference between the vertical distributions of ice, liquid, and mixed-phase clouds from space-based and surface observations is that the space-based observations show much fewer ice clouds and mixed-phase clouds, and slightly more liquid clouds from the surface to $1 \mathrm{~km}$ (Fig. 7). Above $1 \mathrm{~km}$, the two perspectives show similar annual average profiles, with the space observations seeing slightly higher mixed-phase cloud fractions from 3 to $5 \mathrm{~km}$, slightly higher liquid cloud fractions from 0.5 to $3 \mathrm{~km}$, higher ice cloud fractions at $10 \mathrm{~km}$, and lower ice cloud fractions at 2$6 \mathrm{~km}$ (figure not shown), although the month-to-month variability can be larger (Fig. 7). 

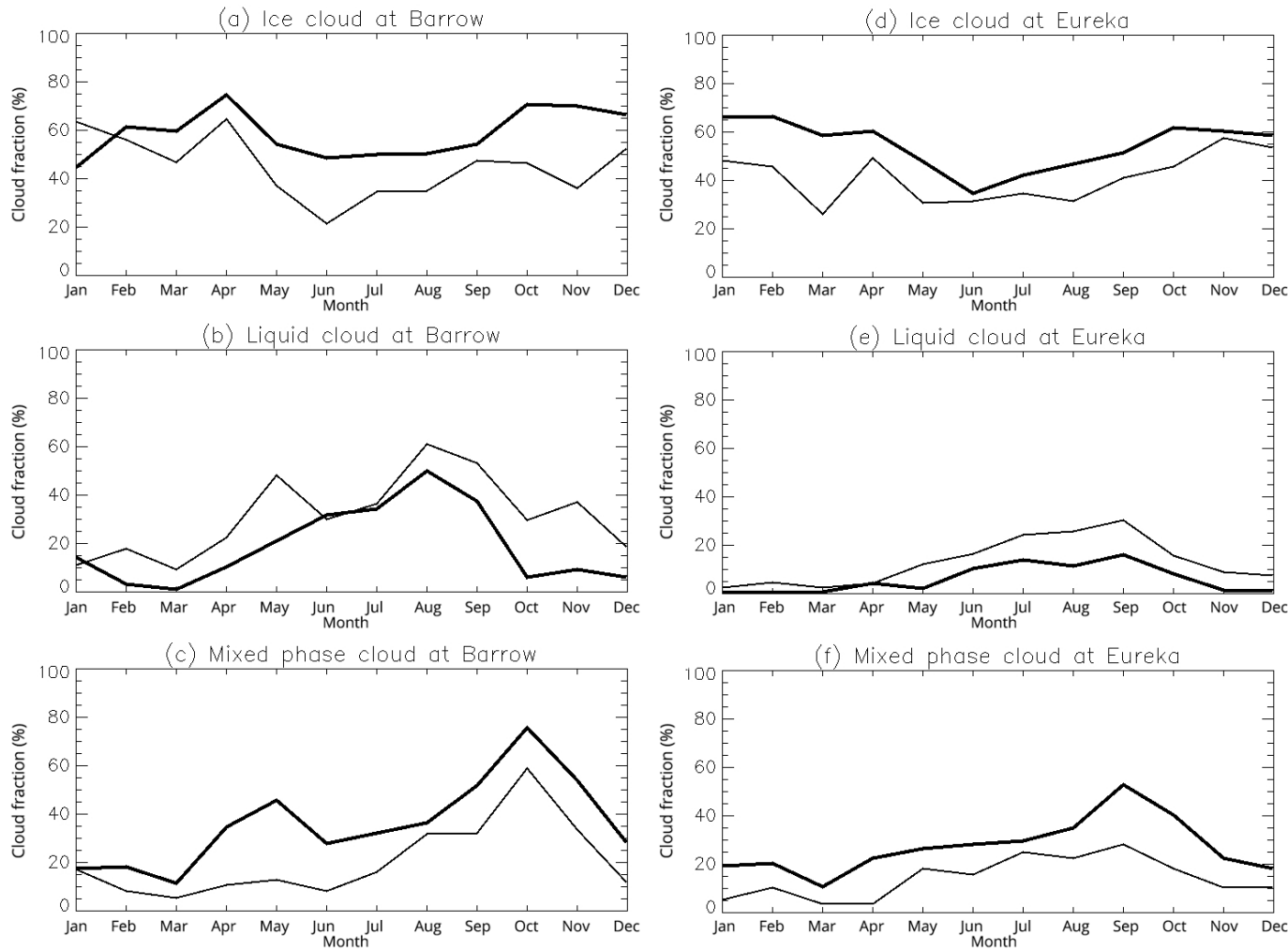

Figure 8. Monthly mean cloud fraction from surface observations (thick line) and 2B-CLDCLASS-lidar (thin line) 2006-2010 (a) ice clouds, (b) liquid clouds, and (c) mixed-phase clouds at Barrow, plus (d) ice clouds, (e) liquid clouds, and (f) mixed-phase clouds at Eureka.

The annual cycle of monthly mean ice clouds from the surface shows greater values throughout the year, except January (Fig. 8a), similar to the mixed-phase cloud amount comparison (Fig. 8c). Liquid cloud monthly means from 2BCLDCLASS-lidar show greater values than those from surface observations in all months except January, June, and July (Fig. 8b). Some of the low-level differences may be the result of space-based measurements having difficulties detecting mixed-phase clouds with low ice concentration, thus classifying these as liquid phase clouds.

\subsubsection{Eureka}

All cloud distributions at Eureka show different annual cycles from those at Barrow. Cloud vertical distributions from space-based observations at Eureka are relatively smoother than at Barrow partly due to the larger number of samples at Eureka. However, the general findings about the differences between space-based and surface observations are similar.

The total cloud fraction vertical distribution at Eureka (Fig. 1b) from surface observations shows the largest values (up to $55 \%$ ) between the surface and $0.5 \mathrm{~km}$, except from June to August when low-level values are less than $25 \%$ and profile maximum values are above $1 \mathrm{~km}$. The maximum cloud fraction in the lower levels at Eureka is considerably smaller than that at Barrow. In the middle levels, the cloud fractions are mainly $10-30 \%$ with a local maximum greater than $30 \%$ from September to November. In the higher levels, most of the cloud fractions are less than $20 \%$.

For the vertical distributions of total cloud fraction from space (Fig. 2d, e, f), CALIPSO $5 \mathrm{~km}$ (Fig. 2d) and $1 \mathrm{~km}$ (figure not shown) show similar patterns with greater values in the CALIPSO $5 \mathrm{~km}$. Both show limited clouds below $0.5 \mathrm{~km}$. A local maximum between 4 and $6 \mathrm{~km}$ appears from October to February in the CALIPSO $5 \mathrm{~km}$. The $2 \mathrm{~B}$ GEOPROF (Fig. 2e) shows few clouds below $1 \mathrm{~km}$ and detailed cloud information above $1 \mathrm{~km}$, with maximum fractions between 1 and $4 \mathrm{~km}$ from September to December. The 2B-GEOPROF-lidar (Fig. 2f) merges information from CALIPSO and CloudSat, and presents a comparable cloud vertical distribution to that from surface observations, except near the surface. In the lower levels, the 2B-GEOPROF-lidar cloud fractions are less than $40 \%$, with a maximum between 30 and $40 \%$ from September to November. In the middle levels, a local maximum cloud fraction of between 30 and $35 \%$ appears between 2 and $4 \mathrm{~km}$ from September to November; a local minimum cloud fraction of less than $15 \%$ appears in March. In the higher levels, the cloud fraction is above $20 \%$ from July to November between 6 and $7.5 \mathrm{~km}$.

Although the total cloud fraction vertical distributions and their annual means at Eureka and Barrow are different 
(Figs. 1 and 4), comparing the space-based cloud vertical distributions and their annual means to those from the surface at Eureka (Figs. 3d, e, f, and 4b) shows qualitatively the same differences as those at Barrow (Figs. 3a, b, c, and 4a). Whether the differences can be generalized to the whole Arctic might be worth further investigation.

The annual cycle of monthly mean cloud amount at Eureka from surface observations shows relatively low values between 56 and $67 \%$ from February to August and high values between 67 and $81 \%$ from September to February (Fig. 5b). Monthly means from space-based observations show generally increasing cloud amounts from March to September, which decrease gradually. The 2B-GEOPROF-lidar shows comparable monthly means as CALIPSO $5 \mathrm{~km}$, and both are greater than those from CALIPSO $1 \mathrm{~km}$ and 2B-GEOPROF, with the least typical from 2B-GEOPROF. All space-based monthly means are noticeably smaller from January to March than those from surface observations, and these negative differences might be due to the relatively higher frequency of clouds below $960 \mathrm{~m}$ only. Monthly means from 2BGEOPROF-lidar and CALIPSO $5 \mathrm{~km}$ are greater from June to August compared to surface observations, which is possibly due to the higher frequency of clouds above $960 \mathrm{~m}$ only, which surface observations might miss (Fig. 6b).

For surface observations at Eureka, ice clouds are the prevalent cloud type from the surface up to $11 \mathrm{~km}$ throughout the year, except in June, July, and August, when there are few ice clouds from the surface to $3 \mathrm{~km}$ (Fig. 9). The maximum ice cloud fraction (up to $40 \%$ ) appears in the lower levels from November to March. In the middle levels, ice cloud fractions are mostly between 15 and $25 \%$, with the exception of lower fractions from June to August. In the higher levels, ice cloud fractions are mostly below $10 \%$, except from July to October. Mixed-phase clouds are common in the lower levels, except in July and August, and in the middle levels from June to September. A maximum mixed-phase cloud fraction between 20 and $30 \%$ appears between the surface and $2 \mathrm{~km}$ from September to October. Liquid phase clouds are mainly less than $5 \%$ throughout the year, except in the lowest $0.5 \mathrm{~km}$ in September and October.

Vertical distributions of ice clouds, liquid clouds, and mixed-phase clouds at Eureka from space-based observations show similar patterns above $1 \mathrm{~km}$ as those from surface observations (Fig. 9). The major differences between surface and space-based observations in the cloud vertical distributions at Eureka (Figs. 8d, e, f, and 9) are similar to those at Barrow (Figs. 7, 8a, b, and c). Major differences between surface and space-based observations include much fewer ice and mixed-phase clouds in the lowest $1 \mathrm{~km}$ from space-based observations; more liquid clouds and mixed-phase clouds above $2 \mathrm{~km}$ in the vertical distributions and annual mean of vertical distributions from space-based observations (figure not shown); comparable monthly mean total cloud amount, higher ice cloud monthly means, lower liquid cloud monthly means, and higher mixed-phase cloud monthly means from surface observations relative to space-based observations. In addition, both satellite and surface observations reveal a key difference in the annual cycles of clouds at Eureka versus Barrow. While both sites have similar annual cycles of ice clouds with a relative decrease in summer (Fig. 8a and d), there are fewer liquid-containing clouds at Eureka, with the annual maximum of these generally shifted to the autumn. These relative annual cycles explain the key differences in the total cloud occurrence fraction over the annual cycle and are explained by generally colder and drier conditions at $\mathrm{Eu}-$ reka relative to Barrow (e.g., Shupe, 2011).

\subsection{Blended cloud vertical distribution at Barrow and Eureka}

While the cloud fraction vertical distributions at Barrow and Eureka show different patterns, the cloud vertical distribution differences between space-based and surface observations are similar for both stations as detailed in Sect. 3.1. Surface observations show detailed and higher values in the lowest $1 \mathrm{~km}$; space observations provide little cloud information in the lowest $0.5 \mathrm{~km}$, limited information between 0.5 and $1 \mathrm{~km}$, and comparable or higher values between 1 and $2 \mathrm{~km}$. In the middle and upper levels, space observations generally show higher values.

Low-level clouds are ubiquitous in the Arctic. For a complete picture of cloud vertical distribution in the Arctic, clouds in the lowest $1 \mathrm{~km}$ a.m.s.l. must be included, and such information is better captured by surface observations. Here, we generate a blended monthly mean cloud fraction vertical distribution for total clouds, ice clouds, liquid clouds and mixed-phase clouds from both surface and space-based observations in monthly means. The monthly mean cloud fraction at every level in the blended product is given as the larger monthly mean cloud fraction of the surface and space-based observations. With this approach, the blended products provide a complete cloud fraction vertical distribution in terms of monthly means by using the strengths of the surface and space-based products.

Figure 10 presents the blended total cloud fraction vertical distributions from 2B-GEOPROF-lidar and surface observations at Barrow and Eureka from 2006 to 2010. The blended product provides a complete picture of the monthly cloud fraction vertical distribution. There is no apparent discontinuity in the cloud fraction vertical distribution near the surface at Barrow or Eureka. Figure 11 shows cloud vertical distributions of ice clouds, liquid clouds, and mixed-phase clouds from 2B-CLDCLASS-lidar and surface observations at Barrow and Eureka from 2006 to 2010. The blended cloud phase vertical distributions from space-based observations look similar to those from surface observations with more complete distributions in the middle and higher levels. The blended product is smoother for Eureka than for Barrow. The cloud fraction vertical distributions are smooth for all cloud phases. 

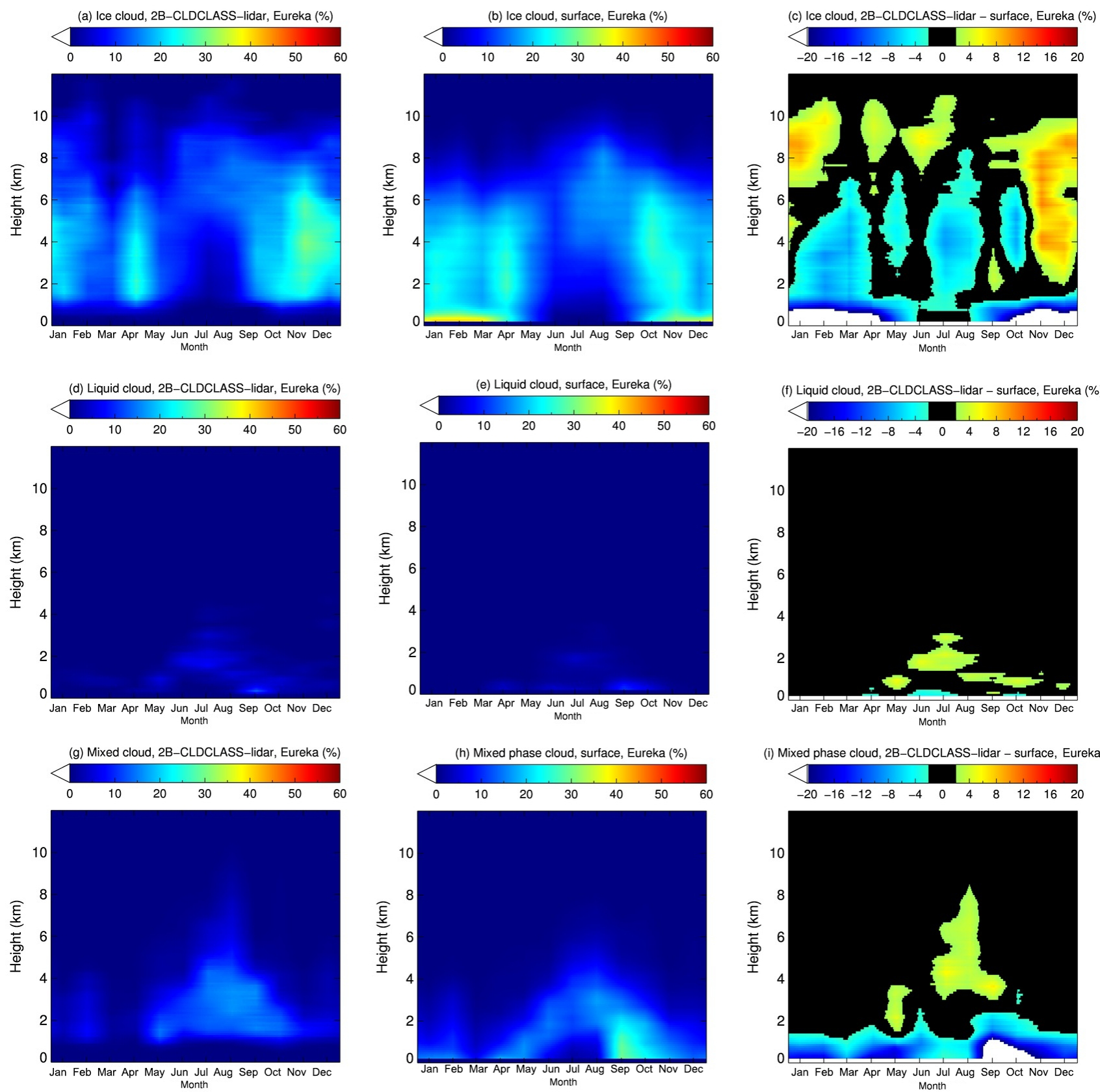

(i) Mixed phase cloud, 2B-CLDCLASS-lidar - surface, Eureka (\%)
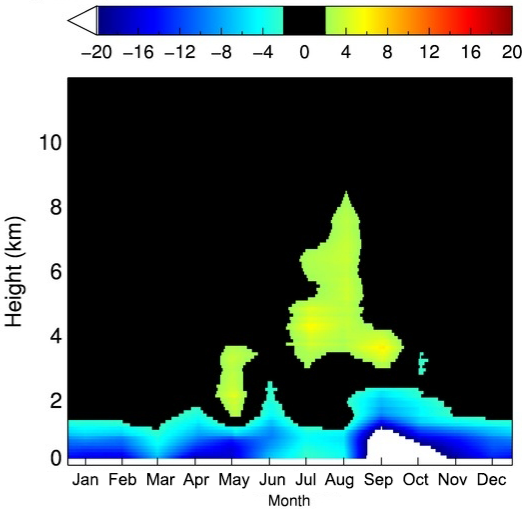

Figure 9. Vertical distributions of ice phase clouds (a-c), liquid phase clouds (d-f), and mixed-phase clouds (g-i) from 2B-CLDCLASSlidar (a, $\mathbf{d}, \mathbf{g})$, from surface observations $(\mathbf{b}, \mathbf{e}, \mathbf{h})$, and the difference of 2B-CLDCLASS-lidar and surface observations at Eureka for 2006-2010.

\subsection{Cloud water content}

In addition to the fractional occurrence of clouds by phase, it is also instructive to examine space and surface-based retrievals of cloud water content. The ice water content and liquid water content vertical distributions from 2B-CWC-RO and surface observations at Barrow are presented in Fig. 12. There is limited information below $1 \mathrm{~km}$ from space-based observations. Based on the space-based observations, the ice water content is less than $40 \mathrm{mg} \mathrm{m}^{-3}$ throughout the year, except from May to August, and in December from 2 to $6 \mathrm{~km}$ when there are higher values up to $100 \mathrm{mg} \mathrm{m}^{-3}$; the liquid water content has high values between 150 and $300 \mathrm{mg} \mathrm{m}^{-3}$ from June to August from 1 to $3.5 \mathrm{~km}$ and in February, September, and October between 1 and $2 \mathrm{~km}$. Surface observations show a low ice water content of $20 \mathrm{mg} \mathrm{m}^{-3}$ and 
(a) Barrow Blended (\%)

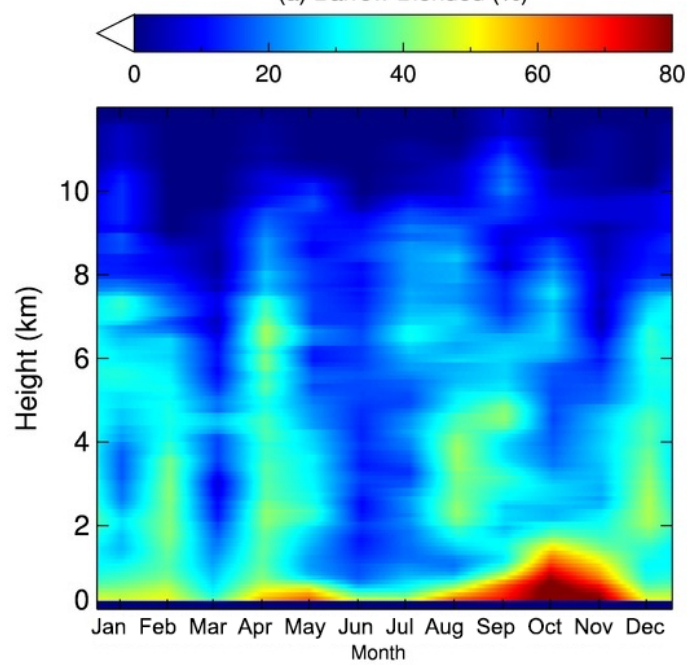

(b) Eureka Blended (\%)
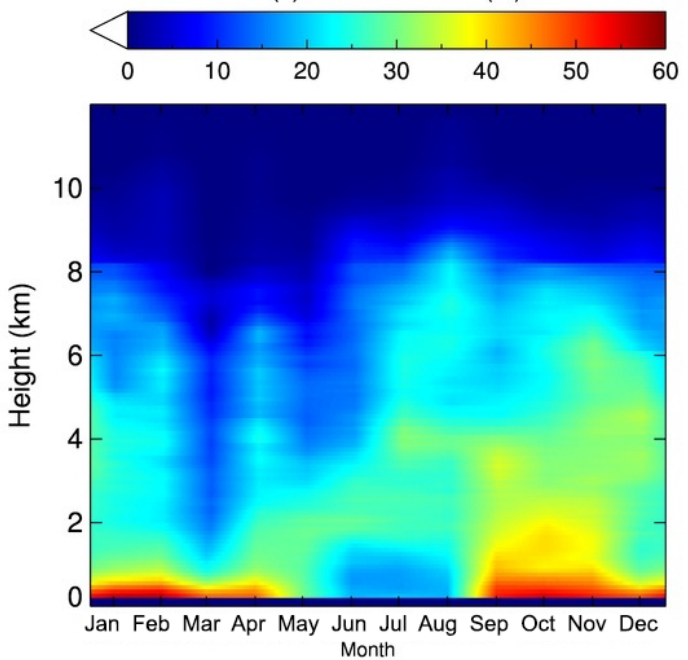

Figure 10. Blended cloud fraction/frequency vertical distribution at Barrow and Eureka with combined surface and space observations from 2B-GEOPROF-lidar for 2006-2010.
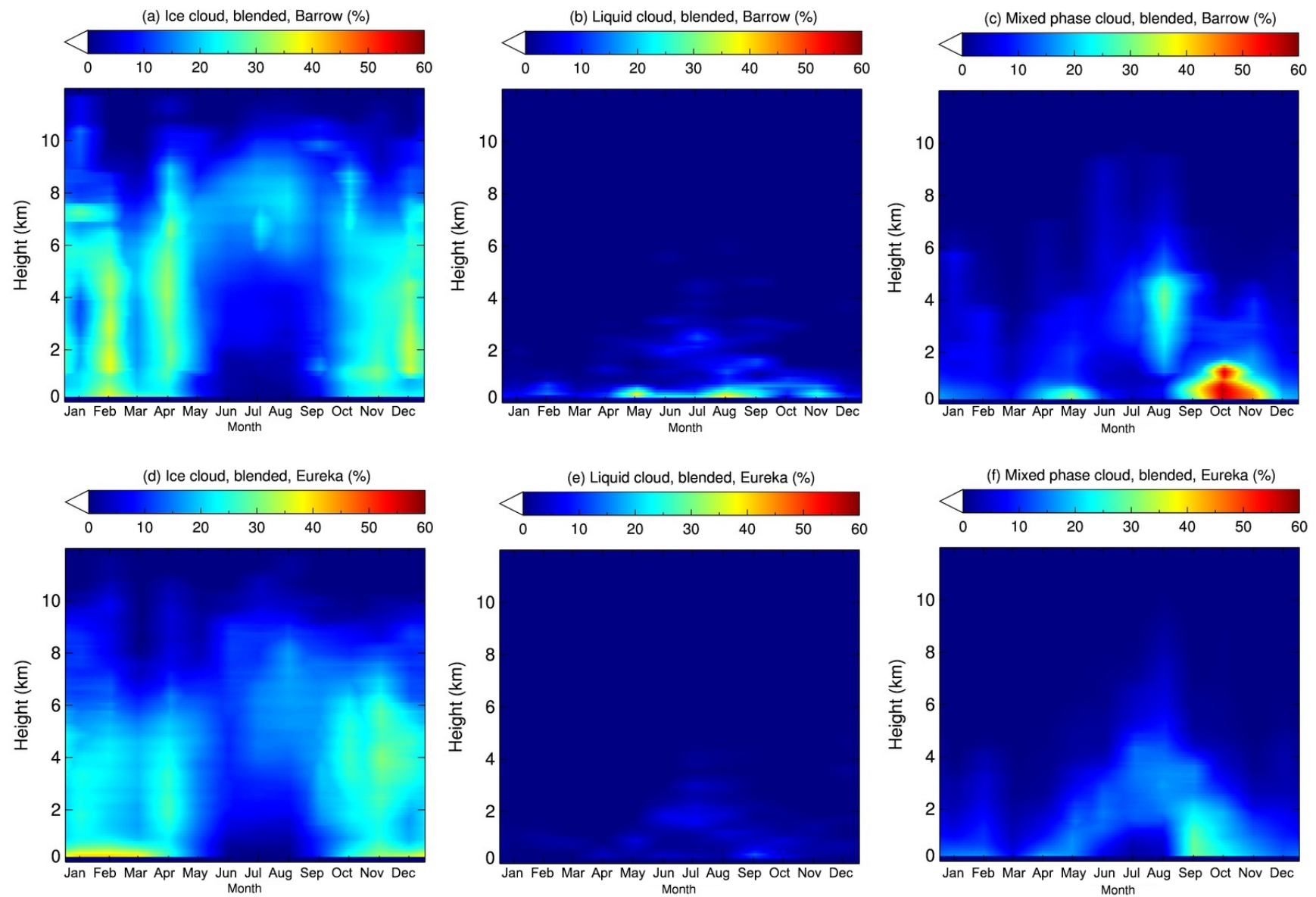

Figure 11. Blended vertical distributions of (a) ice phase clouds, (b) liquid phase clouds, and (c) mixed-phase clouds at Barrow, and (d) ice phase clouds, (e) liquid phase clouds, and (f) mixed-phase clouds at Eureka from 2B-CLDCLASS-lidar and surface observations for 20062010 . 
(a) Ice cloud water content at Barrow $\left(\mathrm{mg} \mathrm{m}^{-3}\right)$

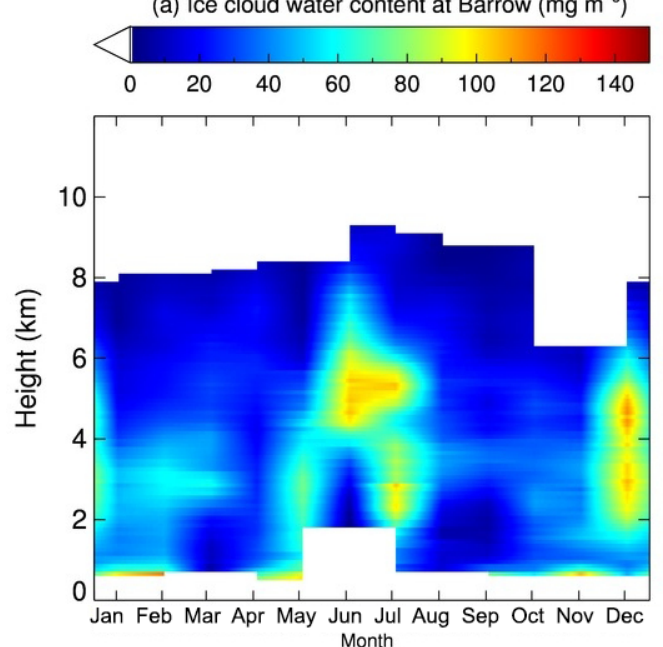

(c) Liquid cloud water content at Barrow $\left(\mathrm{mg} \mathrm{m}^{-3}\right)$
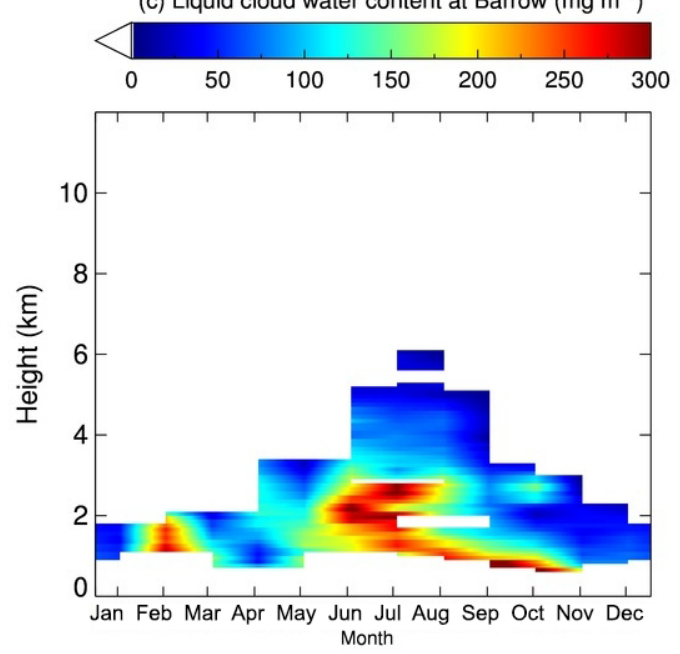

(b) Ice cloud water content, surface, Barrow $\left(\mathrm{mg} \mathrm{m}^{-3}\right)$
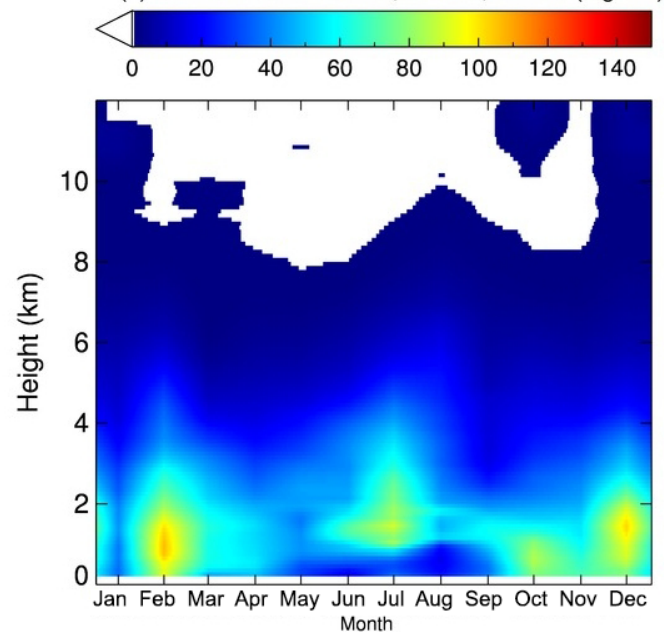

(d) Liquid cloud water content, surface, Barrow $\left(\mathrm{mg} \mathrm{m}^{-3}\right)$
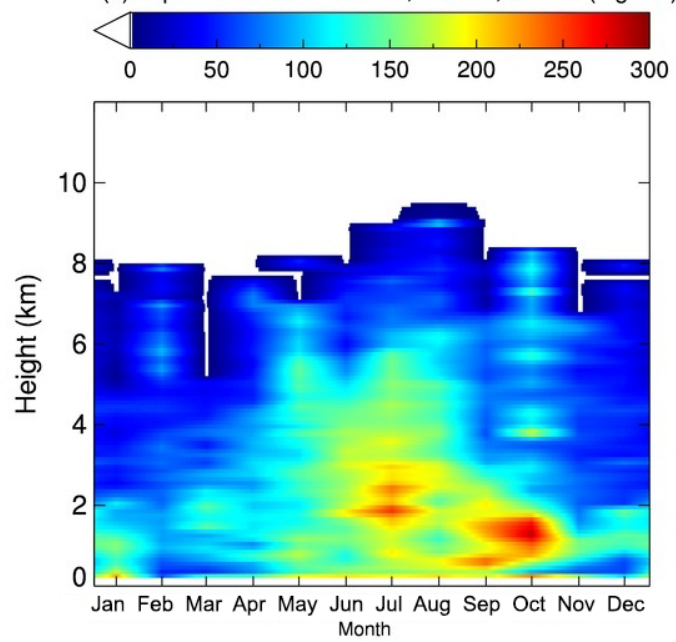

Figure 12. Vertical distributions of cloud water content for ice clouds from (a) 2B-CWC-RO and (b) surface observations, and for liquid clouds from (c) 2B-CWC-RO and (d) surface observations at Barrow for 2006-2010.

less above $4 \mathrm{~km}$, and higher values below $4 \mathrm{~km}$, with maximum values of $60-100 \mathrm{mg} \mathrm{m}^{-3}$ from October to February in the lowest $2 \mathrm{~km}$, and in June and July between 1 and $3 \mathrm{~km}$. Surface-based liquid water content shows high values of $150-250 \mathrm{mg} \mathrm{m}^{-3}$ from May to August from the surface to $5 \mathrm{~km}$ and in September and October from surface to $2 \mathrm{~km}$. The ice water content from the surface and space-based observations both tend to have higher values in June and July, and from December to February, but at different heights. For liquid water content, both surface and space-based observations show high values from June to August in the lowest $3.5 \mathrm{~km}$, and in September and October below $2 \mathrm{~km}$.

At Eureka, the ice water content from space-based observations is less than $40 \mathrm{mg} \mathrm{m}^{-3}$ throughout the year, except from August to October from 2 to $5 \mathrm{~km}$, when the values are around $60 \mathrm{mg} \mathrm{m}^{-3}$, and in April from 2 to $6 \mathrm{~km}$, as shown in Fig. 13. The ice water content from surface observations is also below $40 \mathrm{mg} \mathrm{m}^{-3}$ throughout the year, except from June to October from the surface to $3 \mathrm{~km}$, when the values are between 60 and $80 \mathrm{mg} \mathrm{m}^{-3}$. Liquid water content from both surface and space-based observations shows low values of $75 \mathrm{mg} \mathrm{m}^{-3}$ and less from October to April, and high values from June to August below $3 \mathrm{~km}$, with much higher values from space-based observations.

These comparisons indicate that liquid water content monthly means from space-based and surface observations show similar annual evolution with noticeable magnitude differences. The ice water content monthly means from space and surface observations share little similarities in annual evolution or magnitude. Further investigation of these differences is warranted in order to combine these products for a complete vertical distribution of cloud water content. 

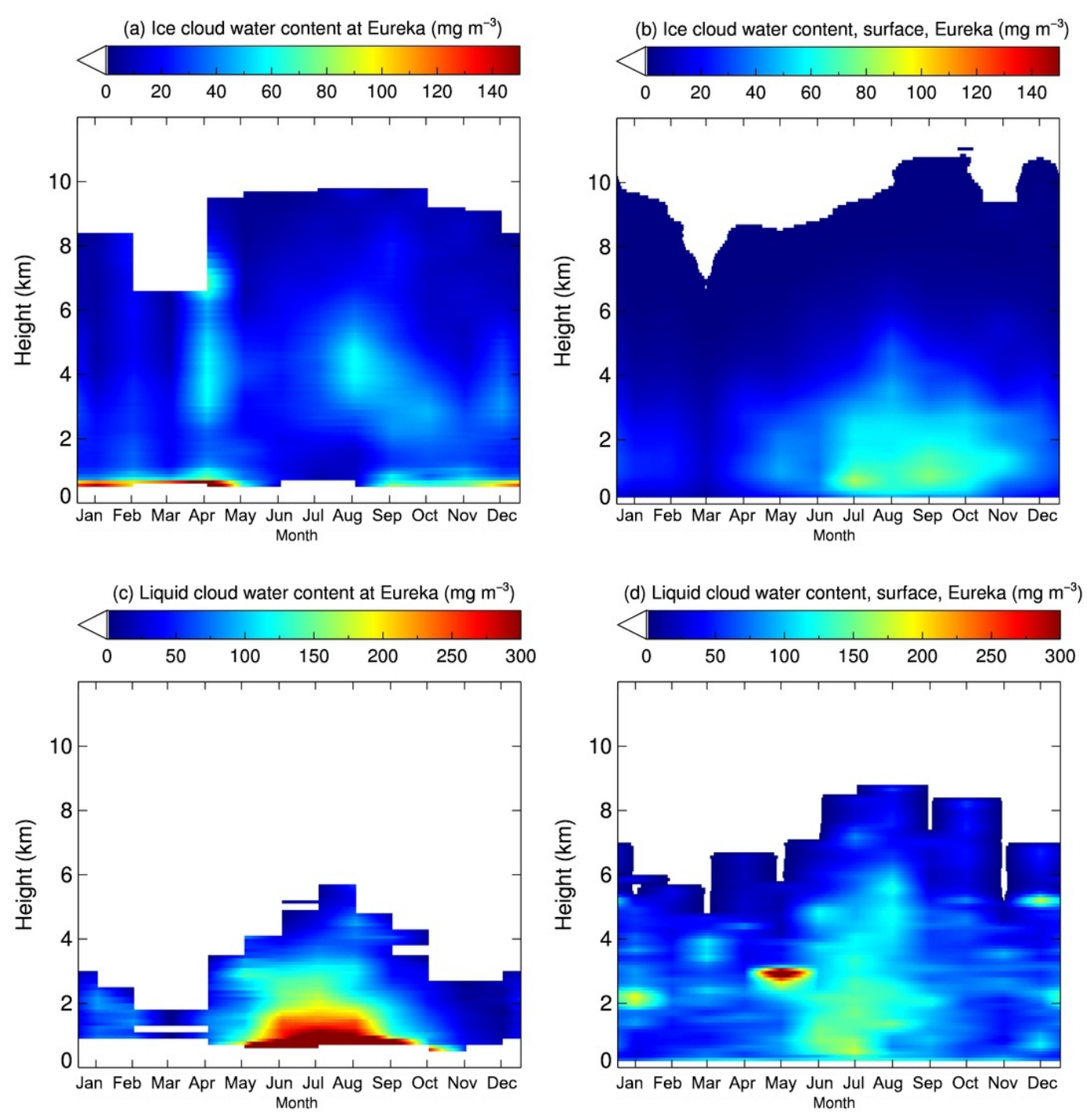

(d) Liquid cloud water content, surface, Eureka $\left(\mathrm{mg} \mathrm{m}^{-3}\right)$
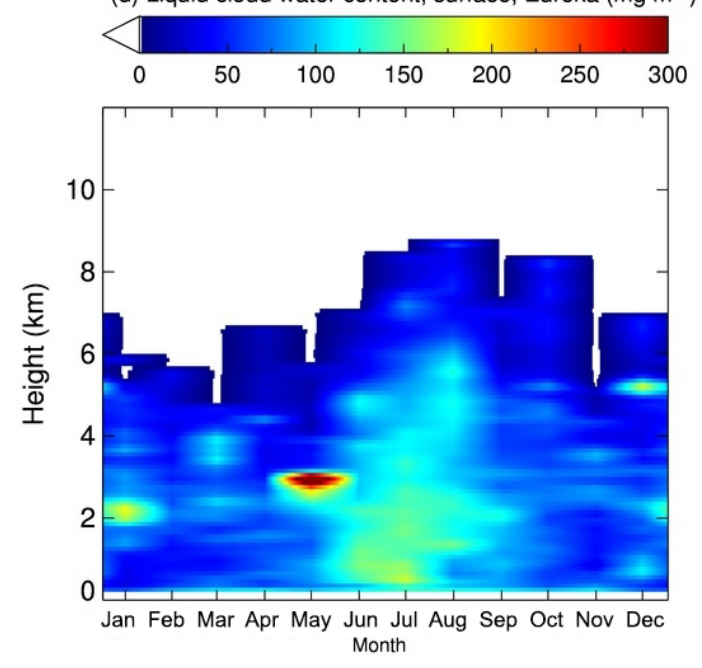

Figure 13. The same as Fig. 12 but for Eureka.

\section{Conclusions}

This study compares the annual cycles of cloud vertical distributions of total cloud, ice cloud, liquid cloud, and mixedphase cloud occurrence fractions from combined surface active lidar-radar observations and from multiple space-based active lidar-radar products at two Arctic atmospheric observation stations, Barrow and Eureka. The primary conclusions are as follows.

All space-based active radar-lidar cloud observations have limitations in the lowest $1 \mathrm{~km}$ a.m.s.l.; the surface measurements have superior performance near the surface, and thereby complement the space-based observations. Surface observations show that the highest total cloud fractions of all clouds, ice clouds, liquid clouds, and mixed-phase clouds appear between the surface and $1 \mathrm{~km}$. All spacebased observations show lower total cloud fractions below

$1 \mathrm{~km}$, with the lowest from 2B-GEOPROF, then CALIPSO $1 \mathrm{~km}$, CALIPSO $5 \mathrm{~km}$, and 2B-GEOPROF-lidar. The annual mean total cloud fractions from space-based observations show $25-40 \%$ fewer clouds below $0.5 \mathrm{~km}$ than those from surface-based observations. Compared to surface-based observations, space-based observations show much fewer ice clouds and mixed-phase clouds, and slightly more liquid clouds from the surface to $1 \mathrm{~km}$. These results are generally consistent with conclusions from previous studies (Protat et al., 2014; Blanchard et al., 2014; Mioche et al., 2015).

Surface observations perform well in describing the cloud vertical distribution at these observation sites. Above $1 \mathrm{~km}$, space-based observations show similar patterns to surface observations, but different magnitudes for total clouds, ice clouds, liquid clouds, and mixed-phase clouds. For satellitebased total cloud fractions, CALIPSO $1 \mathrm{~km}$ shows the lowest values, with higher values from CALIPSO $5 \mathrm{~km}$ especially 
above $6 \mathrm{~km}$, and the highest values from 2B-GEOPROF mainly in the middle level. The 2B-GEOPROF-lidar, which merges CALIPSO and CloudSat, provides the vertical distribution closest to that from surface observations. While the surface observations generally show cloud fractions that are comparable to, or higher than, the satellite-based fractions at most heights, the space observations show greater ice cloud fractions above $9 \mathrm{~km}$, greater liquid cloud fractions in general, and greater mixed-phase cloud fractions above $1 \mathrm{~km}$.

For the annual cycle of the total cloud fraction, monthly means from space-based observations are generally lower than those from surface observations. Each perspective has its limitations, with the surface observations missing some high-level clouds and the space-based sensors missing many low-level clouds. Both estimates are likely lower than the true cloud fraction, if those missed clouds do not overlap with other clouds. Because low clouds are more prevalent at these locations, the surface-based estimate is likely closer to the true total cloud fraction. Annual cycles of monthly mean cloud occurrence by phase show fewer ice and mixed-phase clouds, and greater liquid clouds from space-based observations. This result suggests that active sensor satellite-based estimates of cloud fraction across the Arctic are likely lower than the true cloud fraction, particularly at lower levels and at times of year when low clouds are frequent.

Annual cycles of the total cloud fraction at Barrow and Eureka show a similar evolution, with highest values in autumn, e.g., September and October, and local minimum values in summer, e.g., June and July, and with generally higher monthly cloud fractions at Barrow, except in January and February. Annual cycles of ice clouds at both sites also have a similar evolution, with a relative decrease in summer, and show similar magnitude; liquid-containing clouds at Eureka show lower values than those at Barrow, and its maximum generally shifts to the autumn relative to that at Barrow. These similarities and differences in annual cycles explain the key differences in the total cloud fractions and can be attributed to the generally colder and drier conditions at Eureka relative to Barrow (e.g., Shupe, 2011).

A blended cloud fraction vertical distribution using the larger value of surface and space-based observations can provide a more complete description of the cloud vertical distribution of total clouds, and ice, liquid, and mixed-phase clouds from the surface to $11 \mathrm{~km}$. Such a blended product would be important when considering net atmospheric heating rates above these sites. Such an approach can also be useful in the tropics for a complete depiction of the cloud fraction vertical distribution.

Existing space-based cloud distributions in the lowest $1 \mathrm{~km}$ do not capture all clouds, especially ice and mixedphase clouds. How these missed clouds in the lowest $1 \mathrm{~km}$ affect the radiation flux calculations at the surface and at the top of the atmosphere is a topic of future work and may impact past studies that examine Arctic surface radiative fluxes, as suggested by L'Ecuyer et al. (2008). The blended cloud property vertical distribution can be used as an input to a Monte Carlo radiative transfer model for a more accurate surface radiation flux calculation at these sites. A blended cloud property vertical distribution can also be used to evaluate cloud parameterizations in both weather and climate models (Klaus et al., 2016), to study Arctic atmosphere-sea ice-ocean interactions (Kay et al., 2008; Kay and Gettleman, 2009; Taylor et al., 2015; Liu et al., 2012a), and in other Arctic cloud studies (Devasthale et al., 2011; Liu et al., 2012b; Liu and Key, 2016).

Low-level clouds are frequent in the Arctic and important for the surface radiation balance. While space-based cloud observations from active radar-lidar sensors have been critical for improving our understanding of Arctic clouds and their interactions with other climate components, challenges remain in depicting Arctic low-level clouds from space. Surface observations of clouds at existing atmospheric observatories and a few field campaigns have provided valuable information on Arctic clouds, especially for studying low-level clouds (Tjernström et al., 2014; Uttal et al., 2002). However, such observations are limited in spatial extent and may not represent pan-Arctic cloudiness. Thus, it is critical to combine key information from both space-based and surfacebased cloud measurements to provide the most comprehensive characterization of Arctic clouds possible and to facilitate further understanding of the Arctic climate system.

Cloud frequency from the surface is calculated in the temporal domain, while the cloud fraction from space-based observations is calculated in the spatial domain although near the surface sites. Differences in spatial resolution, viewing angles, vertical resolution, instrument sensitivity to clouds, and retrieval algorithms may all contribute to the differences in the cloud vertical distributions from different instruments. Long-term averages of products may mitigate the impacts of some of these factors. Causes of the remaining differences are worth further investigation.

Data availability. The datasets generated and analyzed during the current study are available from the corresponding author on reasonable request.

Competing interests. The authors declare that they have no conflict of interest.

Acknowledgements. Matthew D. Shupe acknowledges support from the US Department of Energy (DOE) Atmospheric System Research Program (DE-SC0011918) and the National Science Foundation (ARC-0632187). The authors thank Norm Wood, Ralph Kuehn, and Mark Vaughan for their valuable comments on the paper. Yinghui Liu thanks Leanne Avila for editing the paper. Ground-based observations from Barrow were obtained from the DOE Atmospheric Radiation Measurement Program. Groundbased observations at Eureka were obtained from the NOAA Earth 
System Research Laboratory and the Canadian Network for the Detection of Arctic Change (CANDAC). The CALIPSO products from June 2006 to December 2010 were obtained from the Atmospheric Science Data Center at NASA Langley Research Center. The 2B-GEOPROF, 2B-GEOPROF-lidar, 2B-CLDCLASS-lidar, and 2B-CWC-RO products from June 2006 to December 2010 were obtained from the CloudSat Data Processing Center at the Colorado State University.

Edited by: T. Garrett

Reviewed by: A. Devasthale and one anonymous referee

\section{References}

Blanchard, Y., Pelon, J., Eloranta, E. W., Moran, K. P., Delanoë, J., and Sèze, G.: A synergistic analysis of cloud cover and vertical distribution from A-Train and ground-based sensors over the high Arctic station EUREKA from 2006 to 2010, J. Appl. Meteorol. Climatol., 53, 2553-2570, 2014.

Boucher, O., Randall, D., Artaxo, P., Bretherton, C., Feingold, G., Forster, P., Kerminen, V.-M., Kondo, Y., Liao, H., Lohmann, U., Rasch, P., Satheesh, S. K., Sherwood, S., Stevens, B., and Zhan, X. Y.: Clouds and aerosols, Climate Change 2013: The Physical Science Basis, edited by: Stocker, T. F., Qin, D., Plattner, G.-K., Tignor, M., Allen, S. K., Boschung, J., Nauels, A., Xia, Y., Bex, V., and Midgley, P. M., Cambridge University Press, 571-657, doi:10.1017/CBO9781107415324.016, 2013.

Devasthale, A., Tjernstrom, M., Karlsson, K.-G., Thomas, M. A., Jones, C., Sedlar, J., and Omar, A. H.: The vertical distribution of thin features over the Arctic analysed from CALIPSO observations, Tellus B, 63, 77-85, doi:10.1111/j.1600-0889.2010.00516.x, 2011.

Devasthale, A., Tjernström, M., Caian, M., Thomas, M. A., Kahn, B. H., and Fetzer, E. J.: Influence of the Arctic Oscillation on the vertical distribution of clouds as observed by the A-Train constellation of satellites, Atmos. Chem. Phys., 12, 10535-10544, doi:10.5194/acp-12-10535-2012, 2012.

Francis, J. A. and Vavrus, S. J.: Evidence linking Arctic amplification to extreme weather in mid-latitudes, Geophys. Res. Lett., 39, L06801, doi:10.1029/2012GL051000, 2012.

Hélière, A., Lefebvre, A., Wehr, T., Bézy, J.-L., and Durand, Y.: The EarthCARE mission: mission concept and lidar instrument pre-development, IEEE Geoscience and Remote Sensing Symposium, 4975-4978, doi:10.1109/IGARSS.2007.4423978, 2007.

Henderson, D. S., L'Ecuyer, T., Stephens, G., Partain, P., and Sekiguchi, M.: A multisensor perspective on the radiative impacts of clouds and aerosols, J. Appl. Meteorol. Climatol., 52, 853-871, 2013.

Holland, M. M. and Bitz, C. M.: Polar amplification of climate change in coupled models, Clim. Dynam., 21, 221-232, doi:10.1007/s00382-003-0332-6, 2003.

Huang, Y., Siems, S. T., Manton, M. J., Hande, L. B., and Haynes, J. M.: The structure of low-altitude clouds over the Southern Ocean as seen by CloudSat, J. Climate, 25, 2535-2546, 2012.

Kay, J. E. and Gettelman, A.: Cloud influence on and response to seasonal Arctic sea ice loss, J. Geophys. Res.-Atmos., 114, D18204, doi:10.1029/2009jd011773, 2009.
Kay, J. E., L’Ecuyer, T., Gettelman, A., Stephens, G., and O’Dell, C.: The contribution of cloud and radiation anomalies to the 2007 Arctic sea ice extent minimum, Geophys. Res. Lett., 35, L08503, doi:10.1029/2008g1033451, 2008.

Klaus, D., Dethloff, K., Dorn, W., Rinke, A., and Wu, D. L.: New insight of Arctic cloud parameterization from regional climate model simulations, satellite-based, and drifting station data, Geophys. Res. Lett., 5450-5459, doi:10.1002/2015GL067530, 2016.

L'Ecuyer, T. S., Wood, N. B., Haladay, T., Stephens, G. L., and Stackhouse, P. W.: Impact of clouds on atmospheric heating based on the R04 CloudSat fluxes and heating rates data set, J. Geophys. Res.-Atmos., 113, D00A15, doi:10.1029/2008JD009951, 2008.

Li, J., Huang, J., Stamnes, K., Wang, T., Lv, Q., and Jin, H.: A global survey of cloud overlap based on CALIPSO and CloudSat measurements, Atmos. Chem. Phys., 15, 519-536, doi:10.5194/acp15-519-2015, 2015.

Liu, Y.: Estimating errors in cloud amount and cloud optical thickness due to limited spatial sampling using a satellite imager as a proxy for nadir-view sensors, J. Geophys. Res.-Atmos., 120, 6980-6991, 2015.

Liu, Y. and Key, J. R.: Assessment of Arctic cloud cover anomalies in atmospheric reanalysis products using satellite data, J. Climate, 29, 6065-6083, 2016.

Liu, Y., Key, J., Liu, Z., Wang, X., and Vavrus, S.: A cloudier Arctic expected with diminishing sea ice, Geophys. Res. Lett., 39 , L05705, doi:10.1029/2012GL051251, 2012a.

Liu, Y., Key, J. R., Ackerman, S. A., Mace, G. G., and Zhang, Q.: Arctic cloud macrophysical characteristics from CloudSat and CALIPSO, Remote Sens. Environ., 124, 159-173, doi:10.1016/j.rse.2012.05.006, 2012b.

Mace, G. G. and Zhang, Q.: The CloudSat radar-lidar geometrical profile product (RL-GeoProf): Updates, improvements, and selected results, J. Geophys. Res.-Atmos., 119, 9441-9462, doi:10.1002/2013jd021374, 2014.

Mace, G. G., Zhang, Q., Vaughan, M., Marchand, R., Stephens, G., Trepte, C., and Winker, D.: A description of hydrometeor layer occurrence statistics derived from the first year of merged Cloudsat and CALIPSO data, J. Geophys. Res.-Atmos., 114, D00A26, doi:10.1029/2007JD009755, 2009.

Marchand, R., Mace, G. G., Ackerman, T., and Stephens, G.: Hydrometeor detection using Cloudsat - An earth-orbiting 94$\mathrm{GHz}$ cloud radar, . Atmos. Ocean. Technol., 25, 519-533, doi:10.1175/2007jtecha1006.1, 2008.

Mioche, G., Jourdan, O., Ceccaldi, M., and Delanoë, J.: Variability of mixed-phase clouds in the Arctic with a focus on the Svalbard region: a study based on spaceborne active remote sensing, Atmos. Chem. Phys., 15, 2445-2461, doi:10.5194/acp-15-24452015, 2015.

Naud, C. M., Posselt, D. J., and van den Heever, S. C.: A CloudSatCALIPSO View of Cloud and Precipitation Properties across Cold Fronts over the Global Oceans, J. Climate, 28, 6743-6762, 2015.

Overland, J. E. and Wang, M.: When will the summer Arctic be nearly sea ice free?, Geophys. Res. Lett., 40, 2097-2101, 2013.

Protat, A., Young, S. A., McFarlane, S. A., L'Ecuyer, T., Mace, G. G., Comstock, J. M., Long, C. N., Berry, E., and Delanoe, J.: Reconciling Ground-Based and Space-Based Estimates of the Frequency of Occurrence and Radiative Effect of Clouds around 
Darwin, Australia, J. Appl. Meteorol. Climatol., 53, 456-478, doi:10.1175/jamc-d-13-072.1, 2014.

Sassen, K. and Wang, Z.: The clouds of the middle troposphere: composition, radiative impact, and global distribution, Surveys in geophysics, 33, 677-691, 2012.

Serreze, M. C. and Francis, J. A.: The arctic amplification debate, Climatic Change, 76, 241-264, doi:10.1007/s10584-005-9017-y, 2006.

Serreze, M. C. and Stroeve, J.: Arctic sea ice trends, variability and implications for seasonal ice forecasting, Philos. T. R. Soc. A, 373, doi:10.1098/rsta.2014.0159, 2015.

Shupe, M. D.: A ground-based multisensor cloud phase classifier, Geophys. Res. Lett., 34, L22809, doi:10.1029/2007JD008737, 2007.

Shupe, M. D.: Clouds at Arctic atmospheric observatories. Part II: Thermodynamic phase characteristics, J. Appl. Meteorol. Climatol., 50, 645-661, doi:10.1175/JAMC-D-15-0054.1, 2011.

Shupe, M. D. and Intrieri, J. M.: Cloud radiative forcing of the Arctic surface: The influence of cloud properties, surface albedo, and solar zenith angle, J. Climate, 17, 616-628, 2004.

Shupe, M. D., Walden, V. P., Eloranta, E., Uttal, T., Campbell, J. R., Starkweather, S. M., and Shiobara, M.: Clouds at Arctic Atmospheric Observatories, Part I: Occurrence and Macrophysical Properties, J. Appl. Meteorol. Climatol., 50, 626-644, doi:10.1175/2010jamc2467.1, 2011.

Shupe, M. D., Turner, D. D., Zwink, A., Thieman, M. M., Mlawer, E. J., and Shippert, T.: Deriving Arctic cloud microphysics at Barrow, Alaska: algorithms, results, and radiative closure, J. Appl. Meteorol. Climatol., 54, 1675-1689, 2015.

Solomon, S., Qin, D., Manning, M., Chen, Z., Marquis, M., Averyt, K. B., Tignor, M., and Miller, H. L.: Intergovernmental Panel on Climate Change 2007: Synthesis Report, Contribution of Working Group I, II and III to the Fourth Assessment Report of the Intergovernmental Panel on Climate Change, Summary for Policymakers, Climate change 2007: Synthesis Report, Contribution of Working Group I, II and III to the Fourth Assessment Report of the Intergovernmental Panel on Climate Change, Summary for Policymakers, 22 pp., 2007.

Stephens, G. L., Vane, D. G., Boain, R. J., Mace, G. G., Sassen, K., Wang, Z. E., Illingworth, A. J., O’Connor, E. J., Rossow, W. B., Durden, S. L., Miller, S. D., Austin, R. T., Benedetti, A., Mitrescu, C., and CloudSat Sci, T.: The CloudSat mission and the A-train - A new dimension of space-based observations of clouds and precipitation, B. Am. Meteorol. Soc., 83, 1771-1790, doi:10.1175/bams-83-12-1771, 2002.

Taylor, P. C., Kato, S., Xu, K.-M., and Cai, M. C. J. D.: Covariance between Arctic sea ice and clouds within atmospheric state regimes at the satellite footprint level, J. Geophys. Res.-Atmos., 120, 12656-12678, 2015.

Tjernström, M., Leck, C., Birch, C. E., Bottenheim, J. W., Brooks, B. J., Brooks, I. M., Bäcklin, L., Chang, R. Y.-W., de Leeuw, G., Di Liberto, L., de la Rosa, S., Granath, E., Graus, M., Hansel, A., Heintzenberg, J., Held, A., Hind, A., Johnston, P., Knulst, J., Martin, M., Matrai, P. A., Mauritsen, T., Müller, M., Norris, S. J., Orellana, M. V., Orsini, D. A., Paatero, J., Persson, P. O. G., Gao, Q., Rauschenberg, C., Ristovski, Z., Sedlar, J., Shupe, M. D., Sierau, B., Sirevaag, A., Sjogren, S., Stetzer, O., Swietlicki, E., Szczodrak, M., Vaattovaara, P., Wahlberg, N., Westberg, M., and Wheeler, C. R.: The Arctic Summer Cloud Ocean Study (AS-
COS): overview and experimental design, Atmos. Chem. Phys., 14, 2823-2869, doi:10.5194/acp-14-2823-2014, 2014.

Uttal, T., Curry, J. A., Mcphee, M. G., Perovich, D. K., Moritz, R. E., Maslanik, J. A., Guest, P. S., Stern, H. L., Moore, J. A., Turenne, R., Heiberg, A., Serreze, M. C., Wylie, D. P., Persson, O. G., Paulson, C. A., Halle, C., Morison, J. H., Wheeler, P. A., Makshtas, A., Welch, H., Shupe, M. D., Intrieri, J. M., Stamnes, K., Lindsey, R. W., Pinkel, R., Pegau, W., Stanton, T. P., and Grenfeld, T. C.: Surface Heat Budget of the Arctic Ocean, B. Am. Meteorol. Soc., 83, 255-275, doi:10.1175/15200477(2002)083<0255:SHBOTA>2.3.CO;2, 2002.

Vaughan, M. A., Winker, D. M., and Powell, K. A.: CALIOP algorithm theoretical basis document, part 2: Feature detection and layer properties algorithms, Rep. PC-SCI, 202, 87, 2005.

Vaughan, M. A., Powell, K. A., Kuehn, R. E., Young, S. A., Winker, D. M., Hostetler, C. A., Hunt, W. H., Liu, Z., McGill, M. J., and Getzewich, B. J.: Fully Automated Detection of Cloud and Aerosol Layers in the CALIPSO Lidar Measurements, J. Atmos. Ocean. Technol., 26, 2034-2050, doi:10.1175/2009jtecha1228.1, 2009.

Wang, Z., Stephens, G., Deshler, T., Trepte, C., Parish, T., Vane, D., Winker, D., Liu, D., and Adhikari, L.: Association of Antarctic polar stratospheric cloud formation on tropospheric cloud systems, Geophys. Res. Lett., 35, L13806, doi:10.1029/2008GL034209, 2008.

Winker, D. M., Pelon, J., and McCormick, M. P.: The CALIPSO mission: Spaceborne lidar for observation of aerosols and clouds, in: Proceedings of the Society of Photo-Optical Instrumentation Engineers (Spie), Conference on Lidar Remote Sensing for Industry and Environment Monitoring III, Hangzhou, Peoples R China, 2002, WOS: 000182448300001, 1-11, 2003.

Zhao, M. and Wang, Z.: Comparison of Arctic clouds between European Center for Medium-Range Weather Forecasts simulations and Atmospheric Radiation Measurement Climate Research Facility long-term observations at the North Slope of Alaska Barrow site, J. Geophys. Res.-Atmos., 115, D23202, doi:10.1029/2010JD014285, 2010.

Zygmuntowska, M., Mauritsen, T., Quaas, J., and Kaleschke, L.: Arctic Clouds and Surface Radiation - a critical comparison of satellite retrievals and the ERA-Interim reanalysis, Atmos. Chem. Phys., 12, 6667-6677, doi:10.5194/acp-12-6667-2012, 2012. 